\title{
Computational prediction and molecular mechanism of -secretase modulators
}

\section{Mehra, Rukmankesh; Kepp, Kasper Planeta}

Published in:

European Journal of Pharmaceutical Sciences

Link to article, DOI:

10.1016/j.ejps.2020.105626

Publication date:

2021

Document Version

Peer reviewed version

Link back to DTU Orbit

Citation (APA):

Mehra, R., \& Kepp, K. P. (2021). Computational prediction and molecular mechanism of -secretase modulators. European Journal of Pharmaceutical Sciences, 157, [105626]. https://doi.org/10.1016/j.ejps.2020.105626

\section{General rights}

Copyright and moral rights for the publications made accessible in the public portal are retained by the authors and/or other copyright owners and it is a condition of accessing publications that users recognise and abide by the legal requirements associated with these rights.

- Users may download and print one copy of any publication from the public portal for the purpose of private study or research.

- You may not further distribute the material or use it for any profit-making activity or commercial gain

- You may freely distribute the URL identifying the publication in the public portal

If you believe that this document breaches copyright please contact us providing details, and we will remove access to the work immediately and investigate your claim. 


\section{Journal Pre-proof}

Computational prediction and molecular mechanism of $\gamma$-secretase modulators

Rukmankesh Mehra, Kasper P. Kepp

PII: S0928-0987(20)30414-0

DOI: https://doi.org/10.1016/j.ejps.2020.105626

Reference: PHASCI 105626

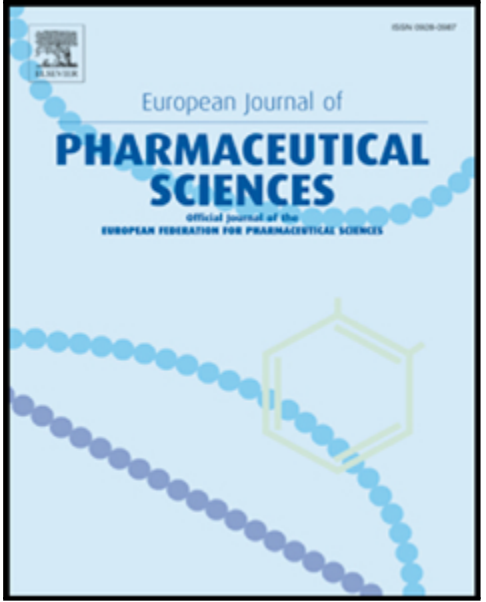

To appear in:

European Journal of Pharmaceutical Sciences

Received date:

10 August 2020

Revised date:

21 October 2020

Accepted date:

23 October 2020

Please cite this article as: Rukmankesh Mehra, Kasper P. Kepp, Computational prediction and molecular mechanism of $\gamma$-secretase modulators, European Journal of Pharmaceutical Sciences (2020), doi: https://doi.org/10.1016/j.ejps.2020.105626

This is a PDF file of an article that has undergone enhancements after acceptance, such as the addition of a cover page and metadata, and formatting for readability, but it is not yet the definitive version of record. This version will undergo additional copyediting, typesetting and review before it is published in its final form, but we are providing this version to give early visibility of the article. Please note that, during the production process, errors may be discovered which could affect the content, and all legal disclaimers that apply to the journal pertain.

(C) 2020 Published by Elsevier B.V. 


\section{Highlights:}

- $\quad \gamma$-secretase modulators may treat Alzheimer's disease, but the action is unknown

- Via computer modeling we found potential modulator binding sites in $\gamma$-secretase

- Pyridopyrazine-1,6-diones bind site 4, between C83 and PS1-TM2 and TM5

- Hydrophobicity and size are important descriptors of drug potency $\left(\mathrm{pIC}_{50}\right)$

- Our models may substantially improve rational design of related drugs 


\title{
Computational prediction and molecular mechanism of $\boldsymbol{\gamma}$-secretase modulators
}

Rukmankesh Mehra ${ }^{1,2}$ and Kasper P. Kepp ${ }^{1, *}$

${ }^{1}$ Technical University of Denmark, DTU Chemistry, DK-2800 Kongens Lyngby, Denmark.

${ }^{2}$ Department of Chemistry, Indian Institute of Technology Bhilai, Sejbahar, Raipur-492015,

Chhattisgarh, India.

*Correspondence: Email: kpj@kemi.dtu.dk

\section{ORCID}

0000-0001-6010-1514, 0000-0002-6754-7348

\begin{abstract}
Selective control over A $\beta$ production via $\gamma$-secretase modulators (GSM) is a promising strategy for treating Alzheimer's disease, yet the specific binding sites and mechanism of action of GSMs remain unknown. Using the recent cryo-electron microscopy structures of substrate-bound $\gamma$ secretase we used two distinct methods to identify four potential binding sites for pyridopyrazine1,6-dione GSMs. We demonstrate binding to site 4 formed between PS1-TM2, PS1-TM5 and the APP-C83-TM, with experimental activity data correlating significantly (95\% confidence) with our computed binding-affinities for this site. Charged protonated GSMs may display higher affinities because of $\pi$-cation interaction with the polar residue Tyr115 of PS1-NTF. Surprisingly, the pIC s0 $_{5}$ of these compounds is largely described $\left(\mathrm{R}^{2}>0.4\right.$ for all of these) by the molecular size, hydrophobicity, and polarizability. We thus believe that we have identified the primary modulator binding site in $\gamma$-secretase for these compounds, as well as strong descriptors of GSM potency. Our results are consistent with the FIST model of $\gamma$-secretase action and suggest that GSMs work in two ways: The binding affinity itself contributes stability to the ternary enzyme-modulator-substrate complex (tight grabbing), thus preventing early release of the substrate and increasing trimming to shorter, innocent $\mathrm{A} \beta$ peptides. At the same time, drug size, hydrophobicity, and polarizability stabilize the more compact semi-open state over the open PS1 state, to make cleavage more precise and complete.
\end{abstract}

Keywords: $\gamma$-secretase; modulators; Alzheimer's disease; drug discovery, binding site. 


\section{Introduction}

Alzheimer's disease (AD) is the main form of dementia and is suffered by more than 30 million people worldwide (Blennow et al., 2015; Dartigues, 2009; Holtzman et al., 2011; Nichols et al., 2019; Prince et al., 2013). Its prevalence increases rapidly with age (Prince et al., 2016). New AD therapies are urgently required as there is currently no effective cure (Hall, 2018). Part of the difficulty relates to the fact that $\mathrm{AD}$ is a complex multifactorial disease with a diverse clinical presentation involving inflammation (Vilalta and Brown, 2018; Zhang and Jiang, 2015), metabolic abnormalities (Hassing et al., 2009; Kepp, 2019; Razay et al., 2006), $\beta$-amyloid (A $\beta$ ) deposition (Masters et al., 1981; Selkoe and Hardy, 2016; Tanzi and Bertram, 2005), tau phosphorylation (Augustinack et al., 2002; Avila, 2006; Bramblett et al., 1993) and imbalances in calcium (Bezprozvanny and Mattson, 2008; Khachaturian, 1987) and other metal ions (Carreiras et al., 2013; Iqbal and Grundke-Iqbal, 2010; Kepp, 2012; Kepp and Squitti, 2019; Morris et al., 2014).

The leading causal hypothesis from a drug discovery point of view has been the amyloid hypothesis (Hardy and Higgins, 1992; Kepp, 2017; Selkoe and Hardy, 2016; Tanzi and Bertram, 2005). A $\beta$ is formed by the action of the intramembrane di-aspartyl protease complex $\gamma$-secretase (De Strooper et al., 2012), which consists of the subunits nicastrin, presenilin, anterior pharynxdefective-1, presenilin enhancer-2 (PEN2) subunits. Presenilin (PS1 or PS2) is the catalytic subunit, which processes the substrate into smaller peptides (Haapasalo and Kovacs, 2011). $\beta$-amyloid precursor protein (APP) is first cleaved by $\beta$-secretase, producing the 99 -residue $\mathrm{C}$-terminal fragment of APP (APP-C99), which is then processed by $\gamma$-secretase into smaller A $\beta$ peptides of variable length (Hardy and Higgins, 1992; Takami et al., 2009; Zhang et al., 2011). The longer peptides $\left(A \beta_{42}\right.$ and $\left.A \beta_{43}\right)$ are more hydrophobic and more prone to aggregation than the shorter peptides $\left(A \beta_{38}\right.$ and $\left.A \beta_{40}\right)$ (Bolduc et al., 2016; Fukumori et al., 2010; Golde et al., 1992; Steiner et al., 2018; Tiwari and Kepp, 2016).

Accordingly, understanding and controlling $\gamma$-secretase production of these different peptides is a main priority, and many pharmaceutical companies, including Neurogenetics, Eisai, Pfizer, Merck, Bristol-Myers Squibb, Janssen, Satori, Roche (Bursavich et al., 2016), work to this end. The molecules should bind to $\gamma$-secretase and change the relative production of the various forms of $A \beta$, rather than strictly inhibiting the enzyme activity, which produces side-effects such as impaired cleavage of Notch, one of the many other substrates of $\gamma$-secretase (De Strooper and Chávez Gutiérrez, 2015; Extance, 2010; Golde et al., 2013; Hopkins, 2011; Imbimbo and Giardina, 2011; Sambamurti et al., 2011; Wolfe, 2012). Such molecules that modulate APP-C99 cleavage towards the formation of shorter $A \beta$ peptides such as $A \beta_{40}$ are called $\gamma$-secretase modulators (GSMs) (Cai et 
al., 2017; Crump et al., 2013; Golde et al., 2013; Johnson and Pettersson, 2017; Oehlrich et al., 2011, 2010; Kevin D. Rynearson et al., 2016; Tate et al., 2012; Wolfe, 2012). Higher enzyme activity tends to correlate with a lower ratio of long vs. short $A \beta$, most notably $A \beta_{42} / A \beta_{40}$ (Sun et al., 2017), raising the question whether fAD is a loss-of-function disease (Kepp, 2016; Shen and Kelleher, 2007). Regardless of the exact aetiology, the $A \beta_{42} / A \beta_{40}$ ratio seems to correlate with the clinical severity of fAD in mutant carriers (Duering et al., 2005; Kumar-Singh et al., 2006; Tang and Kepp, 2018), implying the centrality of $\gamma$-secretase (or presenilin) function.

GSMs of several classes of compounds have been developed, including carboxylic acids, alkenyl, anilines and some larger natural products (Bursavich et al., 2016; Crump et al., 2013; Golde et al., 2013; Johnson and Pettersson, 2017; Kevin D Rynearson et al., 2016; Kevin D. Rynearson et al., 2016; Wolfe, 2012). We performed a literature search of recent GSMs and identified more than 600 unique modulators, including 115 triterpenes, 60 fused oxadiazines, 190 di-and triazoles, 30 piperidines, 40 carbazoles and fenofibrates, and more than hundred other heterocycles; in addition, several patented compounds exhibit nanomolar activities. Researchers from Pfizer (Pettersson group) developed a series of pyridopyrazine-1,6-dione compounds and evaluated their inhibitory activities $\left(\mathrm{IC}_{50}\right)$ for $\mathrm{A} \beta_{42}$ production (Bursavich et al., 2016; Pettersson et al., 2015a, 2015b, 2014). The resulting GSMs are highly potent and feature $\mathrm{IC}_{50}$ values in the nanomolar range. Photoaffinity studies indicate that these compounds preferably bind to the Nterminal fragment (NTF) of PS1 (Pettersson et al., 2015a, 2014). However, the exact binding site, or the variations in active sites, and the mechanism of function of these compounds remains unknown.

Several reports suggest that the modulators bind to some of the transmembrane domains (TM) of $\gamma$-secretase (Crump et al., 2013, 2011; Ohki et al., 2011; Takeo et al., 2014). Phenylpiperidinetype modulators (piperidine acetic acid GSM-1) have been suggested to target the C-terminal side of TM1 (extracellular/luminal) of PS1, causing conformational changes towards the cytoplasmic side of PS1 (Ohki et al., 2011). These acid-based GSMs were also suggested to possibly bind PS1 in the absence of substrate (Crump et al., 2011). In contrast, Uemura et al. reported GSMs that bind after the substrate site is occupied (Uemura et al., 2010). This raises an important question whether true modulators should bind the apo- or holo-state of $\gamma$-secretase, or whether both is possible. If they bind to the apo-state, they risk blocking substrate binding competitively, thus effectively working as inhibitors, which will show up as a lowering of both $A \beta_{42}$ and $A \beta_{40}$ in assays. If only $A \beta_{42}$ is monitored, this possibility is not tested for. Importantly, a typical hypomorphic fAD PS1 phenotype is characterized by lower enzyme activity, less production of both pathways, and increased $A \beta_{42} / A \beta_{40}$ ratios (Sun et al., 2017; Tang and Kepp, 2018). In contrast, binding to the holo- 
state, when C99 is already bound, enables modulation of the activity that changes both qualitatively and quantitatively the $A \beta$ production.

Both nonsteroidal anti-inflammatory drugs (NSAID) derived carboxylic acid-GSMs and nonacid heterocyclic GSMs specifically target presenilin (Crump et al., 2013). However, these two types have distinct preferences for binding sites. They mainly bind to the PS1-NTF (acids, imidazoles) (Crump et al., 2011; Ebke et al., 2011; Jumpertz et al., 2012; Ohki et al., 2011; Pozdnyakov et al., 2013) with a few (NGP-555 modulator; imidazole) also have a high preference for PEN2 than PS1-NTF (Crump et al., 2013; Kounnas et al., 2010). The N-terminal of PEN2, which forms direct contacts with TM4 of PS1 (Watanabe et al., 2005), is reported to modulate PS1 conformation and $\mathrm{A} \beta_{42}$ formation (Isoo et al., 2007; Uemura et al., 2009). Ebke et al. reported that GSMs of diverse structural classes differentially compete in binding and suggested that multiple GSM sites were present (Ebke et al., 2011). In another study, Petit et al. suggested that the extracellular interface between $\gamma$-secretase (PS1, nicastrin) and substrate forms the main GSM binding site (Petit et al., 2019).

Taken together, these studies suggest that different GSM binding sites may be present in $\gamma$ secretase, depending on the nature of the compound, which would greatly complicate the rational development of these drugs. Still, the main hotspots appear to be the PS1-NTF, and the interfaces between PEN2 and PS1-TM4 and PS1/nicastrin and C99. Understanding the molecular details and relevance of these various sites is a central requirement for progress in the area and is the aim of the present paper.

Guiding our study, we consider the model of $\gamma$-secretase activity known as the Fit-(Induce)Stay-Trim (FIST) model (Somavarapu and Kepp, 2017, 2016; Tang et al., 2018), which states that PS1 of $\gamma$-secretase acts as a fist with two conformation states: A semi-open conformation with maximal fitting and affinity of the substrate, maximal staying time, and more precise and extended trimming to shorter A $\beta$ peptides (strong "grabbing" by the "fist", whose main "fingers" are TM2, TM3, TM6, and TM9 of PS1), and an open conformation with less accurate fitting leading to two pathways of cleavage, lower affinity, less staying time, less overall enzyme activity, and increased $\mathrm{A} \beta_{42} / \mathrm{A} \beta_{40}$ ratios, i.e. weaker grabbing by the "fist". PS1 fAD mutations reduce the hydrophobic compactness and stability of the enzyme-substrate complex thus favouring the open conformation (Mehra and Kepp, 2019; Somavarapu and Kepp, 2016; Tang et al., 2019) which can explain the assay data (lower activity, higher $A \beta_{42} / A \beta_{40}$ ratios) for most of these mutants (Sun et al., 2017). In contrast, we postulate that efficient GSMs should work to favour the semi-open, more compact innocent state (tight grabbing), thereby favouring precise and maximal trimming to shorter $\mathrm{A} \beta$ 
peptides (Tang et al., 2018). Simulations of substrate-bound $\gamma$-secretase with both PS1 and PS2 support the presence of these two states when C99 or C83 is bound (Dehury et al., 2019b, 2019a; Mehra et al., 2020).

In the present study, we performed molecular modelling studies using the data for the pyridopyrazine-1,6-dione compounds from Pfizer as a basis, with the aim of identifying both the exact binding sites and the mechanism of action. We screened for potential binding sites, performed molecular docking, MMGBSA computations for the binding affinities, physiochemical property analysis and pharmacophore model constructions. We identified a significant semi-quantitative correlation between the experimental $\mathrm{pIC}_{50}$ and the MMGBSA binding affinities at one particular site in the protein, referred to as "site 4", with other potential sites not showing correlation, indicating that we have identified the real binding site for these compounds. More importantly, several common molecular properties relating mainly to compound size correlated significantly with both binding affinities and experimental $\mathrm{pIC}_{50}$ values, and the hydrophobicity was shown to be an important property governing an increase in the activity and binding of these GSMs. 


\section{Methods}

\subsection{Experimental dataset}

In the process of understanding GSMs, there are many data to choose from, and picking the right data for the problem is a major concern since some of these data are noisy and reflect high chemical diversity, which increases the risk of extra-protein effects in the assays. We mainly emphasized 1) a critical mass of data points; 2) chemical similarity of the compounds; 3) multiple data from the same lab to reduce noise; 4) large spread in compound potency, statistically required for quantifying the modulation; 5) high quality of the compound characterization and assay.

We have previously used a very chemically diverse data set to model GSM activity, finding that generic properties relating to overall binding affinity and engagement of the protein's hydrogen bonds related to potency, although noise is substantial across diverse compound groups (Tang et al., 2018). Here, we used an alternative strategy of minimal chemical diversity, using the data for pyridopyrazine-1,6-dione derivatives produced by researchers from Pfizer, who synthesized these compounds and evaluated the $\mathrm{IC}_{50}$ values for $\mathrm{A} \beta_{42}$ production (Bursavich et al., 2016; Pettersson et al., 2015a, 2015b, 2014). The $\mathrm{IC}_{50}$ values were expressed on a logarithmic scale $\left(\mathrm{pIC}_{50}\right)$ for comparison to the energies computed below. The dataset consists of 51 compounds and is presented in Table S1.

\subsection{Protein model construction}

As explained in the introduction, we emphasize a mechanism of modulation of the cleavage of the bound substrate. This requires knowledge of the substrate-bound protein structure, which has only been available since January 2019 (Zhou et al., 2019). Accordingly, the experimental cryogenic electron microscopy (cryo-EM) structure of $\gamma$-secretase with PDB code 6IYC was used (Zhou et al., 2019). With an average resolution of $2.6 \AA$, it is suited well for the pyridopyrazine-1,6dione dataset since these modulators bind to the PS1-NTF (Pettersson et al., 2015a), and all the transmembrane (TM) helices of this part of the protein are present in the structure. 6IYC contains the transmembrane segment of the substrate APP-C83 (an analogue of APP-C99) and two mutations in PS1 (Q112C and D385A), required for cysteine crosslinking and to prevent enzyme turnover during data collection. To describe modulation of the wild type protein, we, therefore, converted 6IYC into a wild-type by mutating back these two residues (an additional mutation in C83 is not resolved in the structure and was thus not converted). 
The protein was prepared for modelling using the Protein Preparation Wizard of the Schrodinger software (Protein Preparation Wizard, 2018). Hydrogen atoms and missing side chains were added. The protonation states of the residues were assigned at $\mathrm{pH} 7$. All hydrogen bonds were then geometry-optimized and local minimization of the protein complex was performed with a heavy atom RMSD of $0.3 \AA$ using the OPLS3e force field (Roos et al., 2019).

\subsection{Binding site analysis}

In order to identify the possible binding sites within the $\gamma$-secretase-substrate complex, two different tools were used; FTMAP hotspot server (Kozakov et al., 2015) and SiteMap (Halgren, 2009). The identified binding cavities in the transmembrane region were then selected for further analysis. FTMAP docks a fragment library on the potential binding sites on protein and ranks the binding site hotspots based on the fragment binding. SiteMap, on the other hand, uses an approach of finding the cavity regions based on the solvent-accessible surface. It then characterizes the sites in terms of hydrophobic and hydrophilic regions. The hydrophilic regions are subcategorized into hydrogen bond acceptor and donor surfaces. We identified potential binding sites in $\gamma$-secretase specifically focusing on the subunits involving PS1 (chain B), PEN2 (chain D) and C83 (chain E) because the literature reports demonstrate the involvement of these subunits in modulator binding (Crump et al., 2013, 2011; Ohki et al., 2011; Pettersson et al., 2015a; Takeo et al., 2014).

\subsection{Ligand models}

The ligand dataset of the 51 pyridopyrazine-1,6-dione analogues was prepared using the OPLS3e force field in LigPrep (LigPrep, 2018). The possible protonation states were made to reflect $\mathrm{pH} 7 \pm 2$ using Ionizer, and stereoisomers were generated while retaining the specific chiralities. This resulted in 122 ligands when accounting for distinct protonation states and stereoisomers (all final 122 ligands are listed in Table S1). For every compound, one neutral and one protonated state with a charge of +1 was produced with protonated nitrogen on the imidazole. For compounds 20, 21 and 22 (see Table S1), two additional states were generated: One with a charge of +1 with trifluoromethylpyridine nitrogen protonated and one with charge +2 with both trifluoromethylpyridine and the imidazole nitrogen protonated. For compound 78, eight stereoisomers and eight +1 states with protonation on imidazole nitrogen were created, to account for all possible variations of this compound. 


\subsection{Molecular docking and MMGBSA computations}

In order to analyze the potential sites in terms of modulator binding, we generated 3D grids with a minimum of $30 \AA^{3}$ (the volume of a water molecule) up to the default size within the four predicted sites. For sites 1, 2, 3 and 4, the grid sizes were 30, 47, 32 and $30 \AA^{3}$. All the 122 prepared ligands were docked onto these four sites using both SP and XP scoring function of Glide (Halgren et al., 2004). To check whether the modulators bind well in the identified sites, we also docked another dataset of 1000 drug-like decoys from Schrodinger Inc. having an average molecular weight of $400 \mathrm{~g} / \mathrm{mol}$ (Friesner et al., 2004; Halgren et al., 2004). The average weight of the active compounds (51 pyridopyrazine-1,6-diones) was $452 \mathrm{~g} / \mathrm{mol}$. Since molecular size/mass may affect affinity (as in fact shown below also in our case), it is important that the decoys are chemically diverse and resemble in size the active compounds. In our case, the sets differ by only $50 \mathrm{~g} / \mathrm{mol}$, which is not significant.

The docked SP and XP poses were subjected to MMGBSA calculations (Rastelli et al., 2010) using both $0 \AA$ and $4 \AA$ protein flexibilities around the ligand poses, to test sensitivity to protein relaxation in the pockets. We did not use higher flexibilities because earlier observations indicate that MMGBSA-binding affinities correlate highest at low flexibilities, because the experimental protein structure needs to be largely preserved, while still enabling minor relief of steric clashes near the ligands (Mehra et al., 2018b, 2018a).

In order to account for the membrane environment, which is present in the real system (not cryo-EM structure, which represents a sample on a film), MMGBSA was also performed both with and without an implicit membrane model for the protein. The membrane dimensions were defined using the OPM-PPM server (Lomize et al., 2012) and the Prime Refinement panel (Prime, 2018). The implicit membrane defines a slab-shaped region with low dielectric constant similar to the solvent region. Thereby, the low dielectric region removes the rewards incurred by the hydrophilic groups and the penalties suffered by hydrophobic groups in the solvent region. The VSGB solvation model and the OPLS3e force field were used for all computations (Prime, 2018).

\subsection{ADME calculations}

The physicochemical properties were calculated on the 3D ligand poses generated by MMGBSA at $0 \AA$ protein flexibility using QikProp (QikProp, 2018). QikProp calculates 52 ligand properties. We calculated all these properties, while we analyzed only 28 pharmaceutically relevant physical descriptors, which show variability in the dataset such as molecular weight, octanol-water 
partition coefficient, solvent-accessible area, dipole moment, polar surface area, the number of hydrogen bond acceptors and donors, central nervous system activity and blood-brain partition coefficients. In order to analyze the descriptors responsible for binding and experimental activity, we calculated the correlation of the MMGBSA binding affinities and experimental $\mathrm{pIC}_{50}$ values with the QikProp properties.

\subsection{Pharmacophore modelling}

Pharmacophore modelling of the 3D ligand structures produced by MMGBSA on the SP poses at $0 \AA$ flexibility for site 4 , which had the only significant correlation to experimental data as shown below and thus represents the likely binding site, was carried out using Phase (Dixon et al., 2006). Phase implements a tree-based algorithm to identify common pharmacophoric features, which includes hydrophobic $(\mathrm{H})$, aromatic $(\mathrm{R})$, positively charges $(\mathrm{P})$, negatively charged $(\mathrm{N})$, hydrogen bond donor (D) and acceptor (A) features. Common features are identified by aligning a set of the ligand conformers and evaluated based on the survival scores of actives, which is a combination of vector score, site score, volume score, selectivity score and $\log _{10}$ (number of matches). The pharmacophore model enabled us to identify the common interactions exhibited by the active ligands in three-dimensional space, as discussed below in Results. 


\section{Results and discussion}

\subsection{Identification of GSM binding sites within $\gamma$-secretase}

We identified four potential GSM sites that were promising enough to warrant detailed analysis, as explained in detail below. Both SiteMap (Fig. 1a) and FTMAP (Fig. 1b) consistently identified three well-defined sites, which we call here sites 1, 3 and 4 (additional visual details in Fig. S1): Site 1 is located on PS1-TM1 mainly at the PS1-NTF, but also shares an interface with PS1-CTF. We note that this site corresponds well to a literature report suggesting GSM binding to the PS1-TM1 towards the extracellular side (Ohki et al., 2011). Site 3 is present in the middle of the membrane between PEN2, PS1-TM4 and PS1-TM3. At this site, three hotspots were predicted by FTMAP. However, only one SiteMap site covered this region, implying a large site. This site fits well with previous work indicating a modulator site between PS1-TM4 and PEN2 (Watanabe et al., 2005). Site 4 lies between PS1-TM2 and PS1-TM5 on PS2-NTF towards the extracellular side. This site forms an interface with the substrate APP-C83 (chain E, Fig. 1g). We did not identify any literature reports consistent with this site, but given its prevalence and close proximity to PS1-NTF and APP-C83, we also included this site for further analysis. Finally, SiteMap predicted an additional large site, which we call site 2, which covers two FTMAP hotspots (Fig. 1a-1b), spanning a larger space between PS1-TM4 and PEN2 towards the N-terminal of PEN2. The two FTMAP hotspots were $\sim 7 \AA$ away from each other. This extended site resembles well the modulator binding location hypothesized by Watanable et al. (Watanabe et al., 2005) and Kounnas et al. (Kounnas et al., 2010).

Obviously, all of these sites are based on topological and chemical identification without any consideration of the nature of the GSMs themselves and is thus the most generally expected GSM sites that we expect to exist. Importantly, some compound classes may bind exclusively to one of the sites, whereas other compounds bind to other sites, and some compounds may not be very selective. The scaffolds of the specific compounds studied in the present work are shown in Fig. 1c. As mentioned in Methods, all 122 ligands studied in this work were at first considered to bind potentially to any of the four sites, to avoid any bias or restriction in the study. Fig. 1d-1g gives a more detailed overview of the four studied sites 1-4 and the key amino acid residues forming these binding sites. 
(a) SiteMap sites

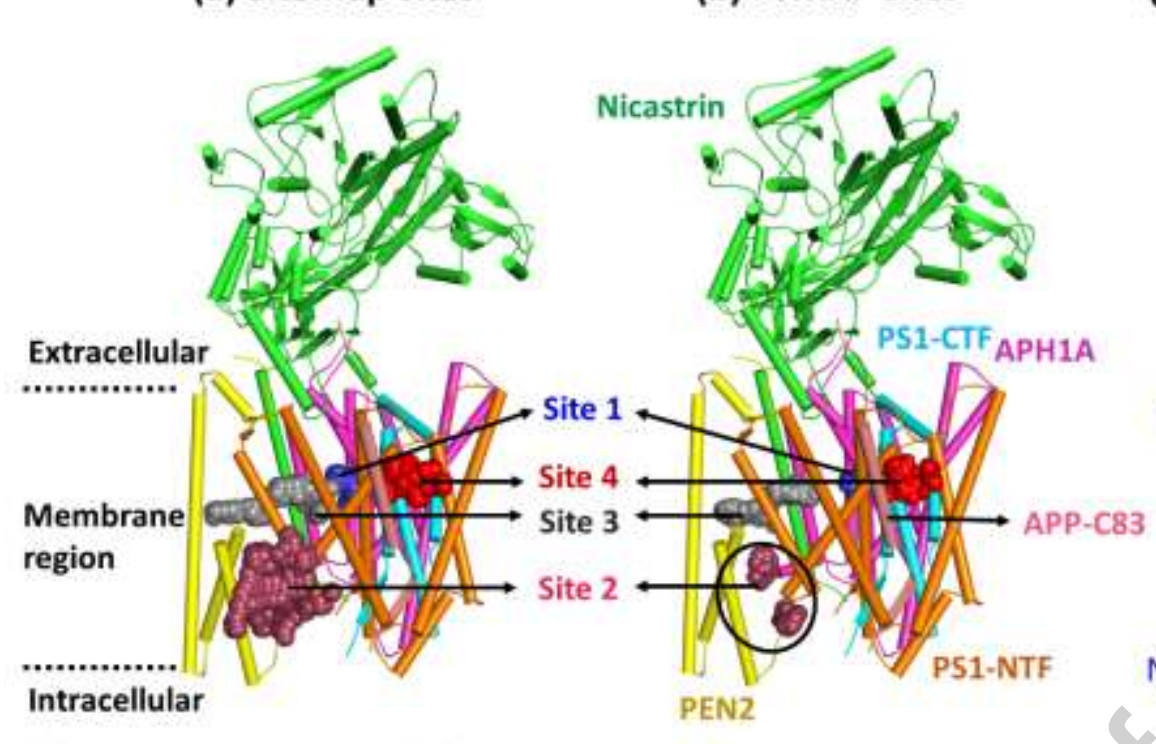

(d) Site 1 (e) Site 2 (b) FTMAP sites

(f) Site 3<smiles>[R1]CCN1CCn2c(ccc(-n3cnc(C)c3)c2=O)C1=O</smiles>

(g) Site 4

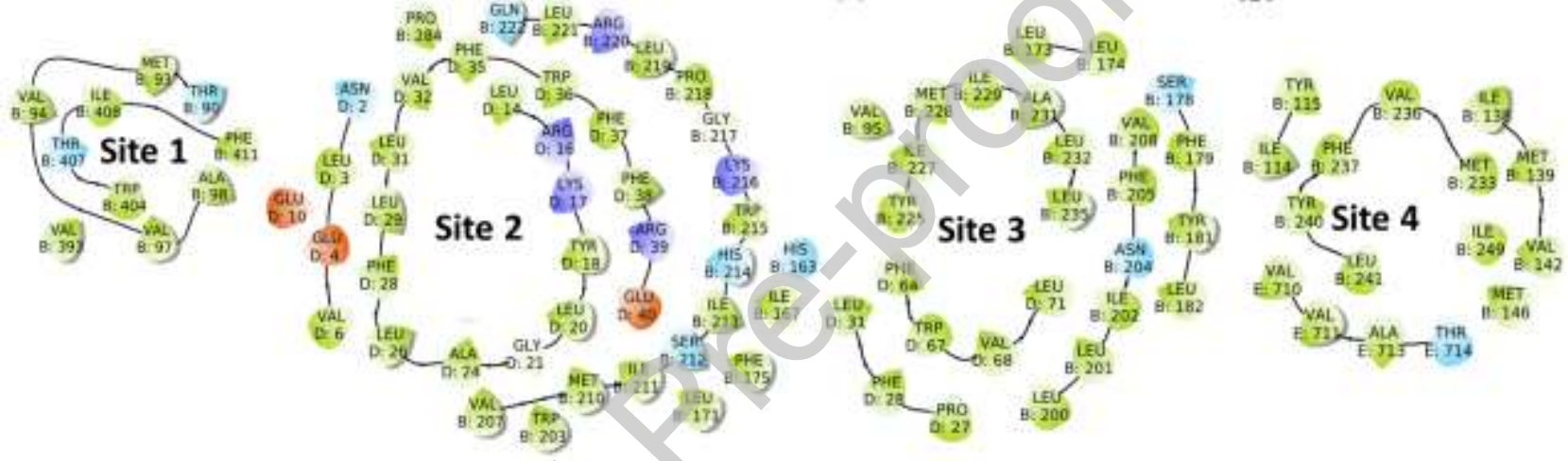

Fig. 1 Potential modulator sites identified in $\boldsymbol{\gamma}$-secretase (6IYC), which consists of four protein subunits comprising nicastrin (green, chain A), PS1 (NTF: orange and CTF: cyan, chain B), APH1A (magenta, chain C), PEN2 (yellow, chain D) and substrate APP-C83 (coral, chain E). (a) Binding sites predicted by SiteMap. (b) Binding sites predicted by FTMAP. (c) Scaffolds of the ligand dataset. (d-g) Residues comprising binding sites: (d) Site 1. (e) Site 2. (f) Site 3. (g) Site 4.

\subsection{Docking scores indicate that decoys are not useful to identify good GSMs}

Molecular docking of the 122 ligand states was performed onto all the four sites described above, and the highest-scoring state was kept for analysis in each case. The resulting violin plots are shown in Fig. S2a. The ligands consistently showed strongest binding to sites 3 and 4 both with simple precision (SP) and extra precision (XP) scoring functions. Assuming that the scores are qualitatively meaningful, and considering the difference in the scores, this suggests that sites 3 and 4 may be the prominent sites for these compounds, although this requires more elaborate affinity calculation (MMGBSA, as described below) to decide. 
We performed Receiver-operator characteristic (ROC) area under curve analysis (AUC) by mixing the 122-compound dataset with 1000 drug-like decoys (Table S2, Fig. S3-S4), we found the SP scoring surpassed the XP, as also reported earlier (Mehra et al., 2015). A ROC value of 0.5 represents random (non-significant) binding behaviour. ROC values of 0.85, 0.64, 0.91 and 0.75 were obtained using SP, and 0.68, 0.54, 0.71 and 0.74 were found using XP for the sites 1-4, respectively (Fig. S4). High ROC would imply that the scoring function differentiates well the actives from the decoys/inactives. However, the actual correlation between experimental $\mathrm{IC}_{50}$ and the docking scores was low using both the scoring functions (Fig. S5 and S6), and thus we consider the good ROC performance an artefact of the decoy approach, which, in direct comparison to the experimental binding data, appear misleading, probably because the decoys are poor proxies of weakly binding ligands to these sites. We thus have little confidence in the use of ROC analysis based on decoy sets, whereas control sets of true weak binders would be useful, as studied directly in the linear regression (Fig. S5-S6).

\subsection{MMGBSA-guided binding mechanism of GSMs}

Due to the poor correlation of docking scores with experimental data, the computationally more intensive and accurate method MMGBSA was used (Fig. S2b). The calculations were done both with and without implicit membrane, since the membrane environment would affect binding differently from the solvent-exposed sites. The various ligand states resulting from protonation and stereoisomers were ranked according to decreasing MMGBSA binding affinities, and the highest affinity states were retained for analysis.

We first note that in all calculations without implicit membrane, no correlation was found for any of the four sites using both SP and XP poses at two protein flexibilities $(0$ and $4 \AA$ around ligands) (Fig. S7-S10). This clearly indicates the importance of handling the fact that $\gamma$-secretase is a membrane protein, and that several sites in the protein are not solvent-accessible, but rather surrounded by lipid groups. For this reason, we performed calculations completely in parallel with the implicit membrane as described in Methods (Fig. S2b, Fig. S11-S14). These results are exclusively discussed below. 
(a) $\Delta G_{\text {bind }}$ at four sites (0 Å flexibility)
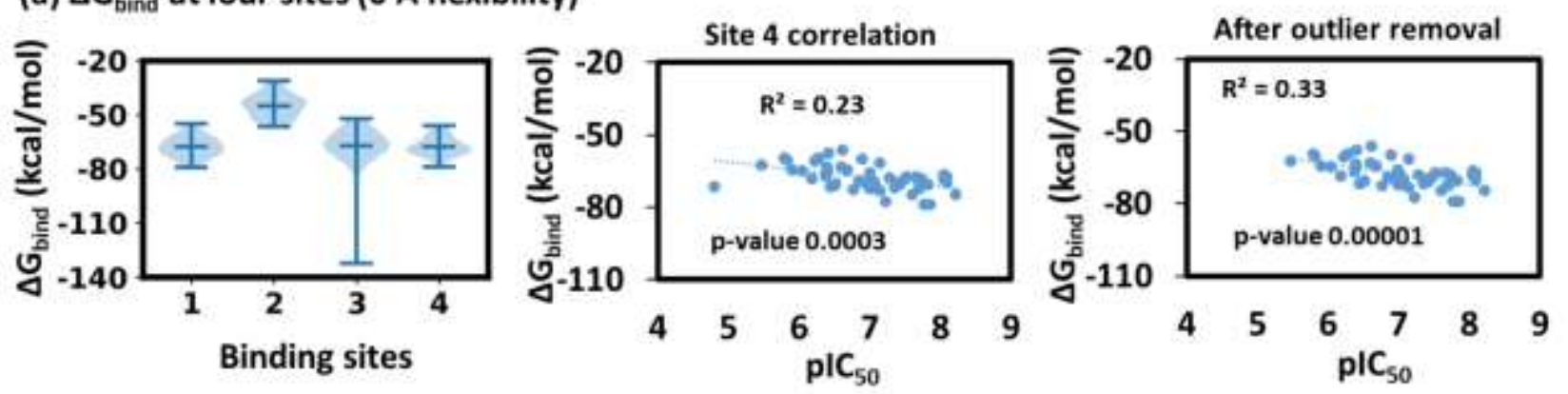

(b) $\Delta G_{\text {bind }}$ at four sites ( 4 Å flexibility)
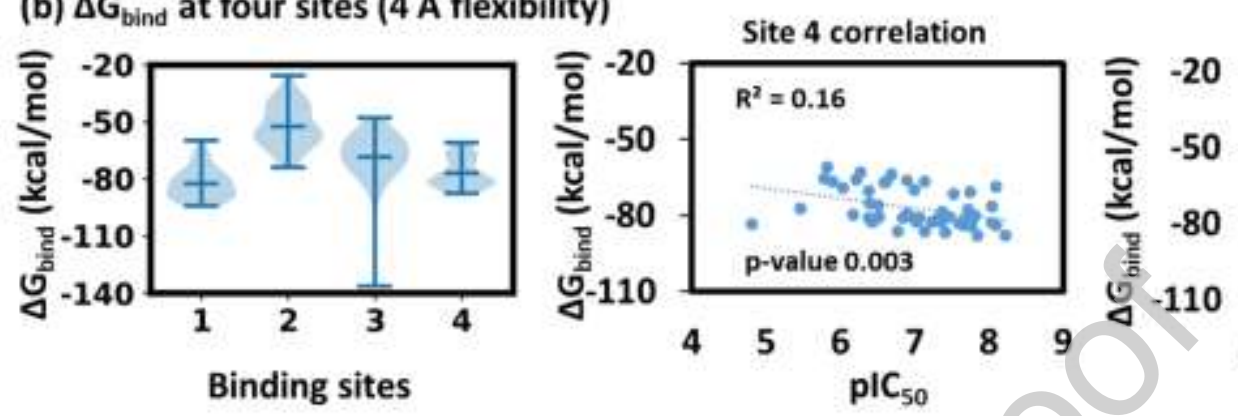

After outlier removal

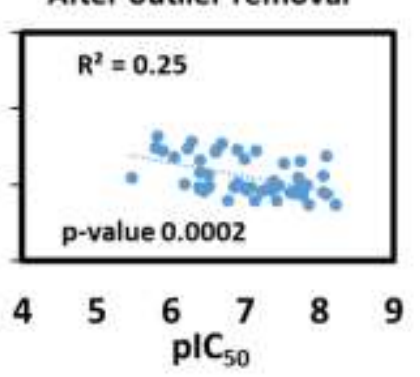

Fig. 2 MMGBSA $\Delta G_{\text {bind }}(\mathrm{kcal} / \mathrm{mol})$ of the $S P$ poses evaluated with the implicit membrane. (a) Distribution of $\Delta \mathrm{G}_{\mathrm{bind}}$ energies of the four sites at $0 \AA$ protein flexibility (left panel), correlation with $\mathrm{pIC}_{50}$ at $0 \AA$ flexibility for site 4 using the full dataset (middle panel) and when removing one extreme outlier (lowest activity; right panel). (b) $\Delta \mathrm{G}_{\text {bind }}$ energies of the four sites at $4 \AA$ protein flexibility (left panel), and correlations with $\mathrm{pIC}_{50}$ as in (a).

The MMGBSA energies computed on the XP docking poses showed no significant correlation (Fig. S13 and S14) as expected since the docking studies already indicated that the SP scoring performed better than XP scoring, which is not unusual (Mehra et al., 2015). SP generates a set of conformations at the binding site and samples torsion angles to identify variable conformations (Friesner et al., 2004). In contrast, XP starts with initial SP sampling and adds additional sampling by its anchor-and-grow method (Friesner et al., 2006). The more restrict requirement for shape complementary with the XP algorithm may disturb the bioactive ligand conformation, perhaps explaining the less accurate scoring. However, the MMGBSA affinities on the SP poses showed significant semi-quantitative correlations with the $\mathrm{pIC}_{50}$ values for site 4 at both protein flexibilities $0\left(\mathrm{R}^{2}=0.23, \mathrm{p}=0.0003\right)$ and $4 \AA\left(\mathrm{R}^{2}=0.16, \mathrm{p}=0.003\right)$ (Fig. 2a-2b, Fig. S11-S12). The direction of correlation was also meaningful: the binding affinity increased (low $\Delta \mathrm{G}_{\text {bind }}$ ) with increasing activity (high $\mathrm{pIC}_{50}$ and low $\mathrm{IC}_{50}$ ). More importantly, when a single outlier with the lowest pIC $\mathrm{I}_{50}$ (compound 15 with $\mathrm{pIC}_{50}=4.8$ and $\mathrm{IC}_{50}=15800 \mathrm{nM}$ ) was removed, correlation improved substantially to $\mathrm{R}^{2}=0.33(\mathrm{p}=0.00001)$ with $0 \AA$ flexibility and $\mathrm{R}^{2}=0.25(\mathrm{p}=0.0002)$ with $4 \AA$ 
flexibility. Considering the noise of structures, experimental data, and computational uncertainties, this result is remarkable and strongly supports that site 4 is the real binding site of the studied compounds.

For compound 78 (J. Med Chem., 2016, 59, 7389, Table S1), eight stereoisomers and eight protonation states with +1 charge are possible although activity $\left(\mathrm{IC}_{50}\right)$ was reported just for one stereoisomer (variant 78-1, Table S1). These various states were generated by LigPrep and analyzed completely, keeping the remaining data the same (Fig. S15-S20). The correlations were generally similar to those reported above. The MMGBSA computations on SP poses again showed significant semi-quantitative correlations with $\mathrm{pIC}_{50}$ for site 4 with $\mathrm{R}^{2}=0.16(\mathrm{p}=0.004)$ using all 51 data points and $\mathrm{R}^{2}=0.24(\mathrm{p}=0.0003)$ after one outlier removal (with lowest $\left.\mathrm{pIC}_{50}\right)$ at $0 \AA$ flexibility (Fig. S21). We conclude that the exact stereoisomer and charge state, which affects affinity, does so to a small extent relative to the overall variation in the data and thus does not add new information. Further analysis discussed below thus concentrated on the experimentally reported variant (variant 78-1 and its +1 protonation state 78-9; Table S1) with the remaining dataset and the MMGBSA data computed on SP poses at $0-\AA$ protein flexibility.

It is not surprising that site 4 is the only site that shows significant correlations to experimental data (Fig. S11-S12, S17-S18), since these compounds belong to the same class (pyridopyrazine-1,6dione), have similar scaffolds (Fig. 1c), and thus can be expected to exhibit the same binding mechanism. However, we stress that other compound classes may bind to other of our four identified sites, and perhaps several of them.

In terms of mechanism, site 4 lies at an interface between the PS1-NTF and APP-C83. It is highly likely that the studied compounds stabilize the ternary complex with the bound substrate by interacting with both the PS1 and APP-C83 residues, thereby increasing the staying time and trimming extent of the substrates. This mechanism would be in accordance with the FIST model, described above. Thermodynamically and kinetically, it amounts to contributing the additional binding affinity in site 4 to stabilizing of the enzyme-substrate complex, which will lower the Michaelis constant, $\mathrm{K}_{\mathrm{M}}$. Mechanistically, it is likely to occur via specific interactions that favour the semi-open over the open conformation state (tight grabbing by the fist).

So far in our study, all compounds, due to their similarity, were assumed to all bind to the same site during the comparison. To check whether the modulators, despite their similarity, actually bind to different sites, we combined the binding affinities for all four sites for the SP poses at $0 \AA$ flexibility, sorted them according to decreasing affinities and then selected only the highest affinity score for each compound, regardless of site, keeping only the highest affinity score of each 
compound for correlation analysis (Fig. S22). We found no correlation $\left(\mathrm{R}^{2}=0.04\right.$; after two outlier removals $\left.\mathrm{R}^{2}=0.05\right)$, strongly indicating that a large majority of the dataset compounds bind at site 4.

We further calculated the averages and standard deviations (SD) of the MMBGSA binding affinities at the four sites (Table S3). Similar averages of -67.70 (SD 5.49), -67.26 (SD 11.07) and 67.48 (SD 5.09) were found for the sites 1, 3 and 4, respectively. However, the SD for site 3 was relatively high. Site 2 displayed a distinct behaviour, with a distinctly lower average binding affinity, i.e. -44.90 (SD 6.26). This may be due to the larger space in the site, which could make binding less specific. Site 2 may thus fit modulators with a diverse binding mechanism. Since our dataset consists of similar compounds, it is highly likely that they bind to the same site (site 4) and not site 2 .

\subsection{Impact of stereoisomers and protonation states on GSM potency}

In the dataset, three compounds existed as stereoisomers. Two of these existed as two stereoisomers with reported distinct activities: Compounds 19 and 20 (ACS Med. Chem. Lett., 2015, 6, 596) ,(Pettersson et al., 2015b) and compounds 29 and 30 (Bioorg. Med. Chem. Lett., 2015, 25, 908) (Table S1)(Pettersson et al., 2015a). However, compound 78(Bursavich et al., 2016) (J. Med Chem., 2016, 59, 7389) (Table S1) exist as potentially eight stereoisomers and the activity has been reported only for one of these (variant 78-1, $\mathrm{IC}_{50} 14 \mathrm{nM}$; Table S1). To account for the potential variation in binding affinity and potency that this may cause, we analyzed the binding of these variants and their various protonation states at site 4 (MMGBSA of SP poses at $0 \AA$ flexibility) (Fig. S23). We found that the two stereoisomers 19/20 and 29/30 showed similar binding affinities in the range -35 to $50 \mathrm{kcal} / \mathrm{mol}$ at site 4 . However, their +1 -charged protonated states displayed markedly higher affinities of -57 to $-74 \mathrm{kcal} / \mathrm{mol}$. The experimental activities of these stereoisomers 19/20 and 29/30 were 20/85 nM and 6/389 nM respectively, corresponding well with the binding affinities. Stereoisomers 19/20 exhibit similar activities, which is well explained by the computed binding affinities $(-36 \mathrm{kcal} / \mathrm{mol}$ for neutral and $-70 \mathrm{kcal} / \mathrm{mol}$ for +1 -charged ligands). The activities of 29/30 differ by $\sim-380 \mathrm{nM}$, which is reflected by their binding affinities of -50 and $-35 \mathrm{kcal} / \mathrm{mol}$ for the neutral, and -74 and $-57 \mathrm{kcal} / \mathrm{mol}$ for the +1 -charges state, respectively.

Similarly, the various compound 78 stereoisomers had computed $\Delta \mathrm{G}_{\text {bind }}$ values from -48 to -79 $\mathrm{kcal} / \mathrm{mol}$ when bound to site 4 . Their neutral stereoisomers generally had lower binding affinities of -48 to $-67 \mathrm{kcal} / \mathrm{mol}$ than the protonated states with +1 net charge, which displayed affinities from - 
58 to $-79 \mathrm{kcal} / \mathrm{mol}$. Thus, the protonation state at the actual target is critical for the potency of these particular compounds and is virtually unpredictable.

The analysis of the effect of protonation state variations near physiological $\mathrm{pH}$ indicates that charge interactions may substantially affect the potency of some of the ligands. Supporting this observation is the fact that site 4 contains several polar residues and in particular, Tyr115 of PS1NTF is highly likely to engage in $\pi$-cation interactions with the protonated GSM (discussed below).

\subsection{Physico-chemical properties correlating with $\mathrm{IC}_{50}$}

It is apparent from the above analysis that the binding affinity of the GSM to site 4 explains a substantial part of the potency of the drug in assays. It is possible that other properties of the drugs are important as well, since the mechanism of GSMs is not generally known, and it is not necessarily the case that stronger binding will provide a modulation of the C99 cleavage, for example, if the site induces strong binding but is not close to the active site of $\gamma$-secretase.

To understand in more detail the specific molecular properties that contribute to GSM potency, we analyzed first the correlation between the MMGBSA-computed binding affinities $\left(\Delta \mathrm{G}_{\mathrm{bind}}\right)$ and several physiochemical features for all the four sites, calculated using QikProp(QikProp, 2018) (Fig. 3 for the best-correlating properties of site 4 and Tables S4-S7 for all properties in all four sites, including their p-values). The ligand poses at site 4 provided the best correlations as expected, since it produces the best correlation for $\Delta \mathrm{G}_{\text {bind }}$ in the first place. Among all studied properties, we found that molecular weight (Fig. 3a; $\mathbf{R}^{2}=0.12$ ), volume (Fig. 3b; $\mathbf{R}^{2}=0.21$ ), solvent accessible surface area (Fig. 3c; $R^{2}=0.21$ ), hydrophobic surface area (FOSA, Fig. 3d; $R^{2}=0.13$ ), shape (glob, Fig. 3e; $R^{2}=0.12$ ), polarizability (QPpolrz, Fig. 3f; $\left.R^{2}=0.16\right)$, the hexadecane-gas partition coefficient (QPlogPC16, Fig. 3g; R ${ }^{2}=0.10$ ) and the octanol-gas partition coefficient (QPlogPoct, Fig. 3h; $\mathrm{R}^{2}=0.10$ ) all can explain some of the binding affinity of the GSMs at statistical significance $(\mathrm{p}<0.05 ; 95 \%$ confidence, linear regression test, please see $\mathrm{p}$-values in Table S7) (Fig. 3).

All the correlating properties can be reduced to an effect of the size and hydrophobicity on the binding affinity of the GSMs, which is not surprising, as binding affinities, all-else equal, tend to scale with the size of small and moderate-sized ligands, and this is particularly true for hydrophobic interactions that favour protein-ligand association over solvation (Kuntz et al., 1999). The fact that binding affinity partly explains GSM activity and is governed by ligand size and hydrophobicity fits very well with previous studies of GSM activity using very distinct compound classes (Tang et al., 
2018), and observations that the clinical severity of fAD-causing PS1 mutations tend to correlate with the loss of stability and hydrophobic packing of the enzyme complex (Somavarapu and Kepp, 2016). Both observations agree with the FIST model discussed above.

(a) Molecular weight

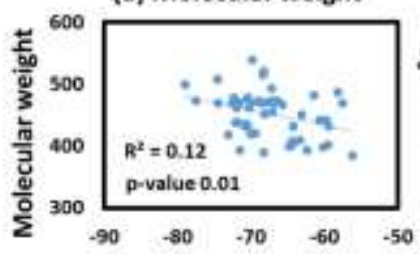

(e) glob

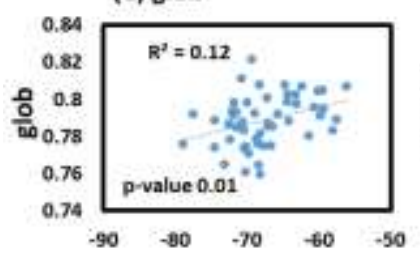

(b) Volume

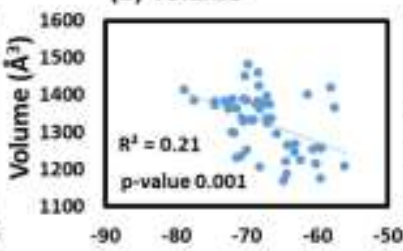

(f) QPpolrz

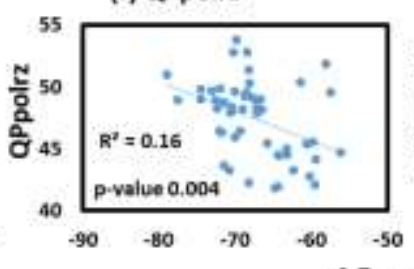

(c) SASA

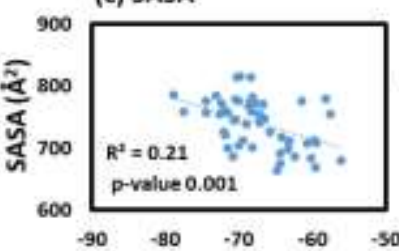

(g) QPlogPC16

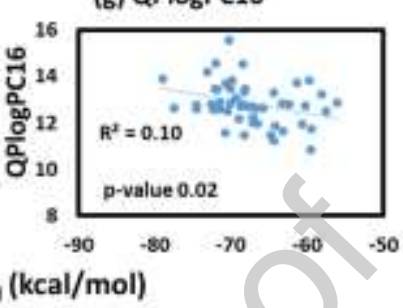

(d) FOSA

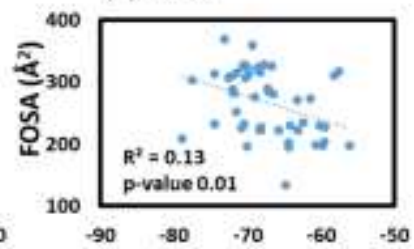

(h) QPlogPoct

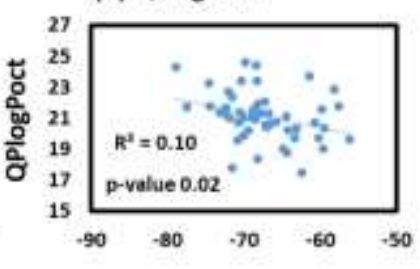

Fig. 3 Significant correlations between GSM binding affinities $\left(\Delta G_{b i n d}\right.$ from MMGBSA at site 4; SP poses at $0 \AA$ A flexibility) and physicochemical properties. (a) Molecular weight of GSM. (b) Volume of GSM. (c) Total solvent-accessible surface area (SASA). (d) Hydrophobic surface area (FOSA). (e) Globular shape (glob). (f) Polarizability (QPpolrz). (g) Hexadecane-gas partition coefficient (QPlogPC16). (h) Octanol-gas partition coefficient (QPlogPoct).

Accordingly, we find that the hydrophobic SASA (FOSA, Fig. 3d) rather than the hydrophilic SASA (FISA, Table S7) contributes to the binding affinity of the GSMs. The globular shape of the molecules correlated inversely to the affinities (Fig. 3e); it has values between 0 and 1 , where 1 represents the perfectly globular compound. Not surprisingly, as these binding sites are not very buried and globular, but rather extended and surface-exposed, an extended shape of the GSM seems to contribute to strong binding affinity.

\subsection{Structure-activity relationships}

Since binding affinity was shown above to explain some, but not necessarily all of GSM potency, we also investigated whether any physico-chemical properties describe GSM activity ( $\mathrm{pIC}_{50}$ ) directly (Fig. 4, Table S8). Significant correlations (95\% confidence) were seen for the molecular weight $\left(R^{2}=0.49\right)$, volume $\left(R^{2}=0.45\right)$, SASA $\left(R^{2}=0.40\right)$, FOSA $\left(R^{2}=0.12\right)$, the weakly polar part of SASA (WPSA, $\mathrm{R}^{2}=0.12$ ), the number of hydrogen bond acceptors (accptHB, $\mathrm{R}^{2}=0.22$ ), 
the shape (glob, $\left.\mathrm{R}^{2}=0.16\right)$, polarizability $\left(\mathrm{QPpolrz}, \mathrm{R}^{2}=0.49\right)$, hexadecane-gas $\left(\mathrm{QPlogPC} 16, \mathrm{R}^{2}=\right.$ 0.11), octanol-gas (QPlogPoct, $\left.\mathrm{R}^{2}=0.42\right)$ and water-gas partition coefficients $\left(\mathrm{QPlogPw}, \mathrm{R}^{2}=\right.$ $0.19)$, the aqueous solubility $\left(\mathrm{CIQP} \log S, \mathrm{R}^{2}=0.16\right)$ and the polar surface area $\left(\mathrm{PSA}, \mathrm{R}^{2}=0.13\right)$.

(a) Molecular weight

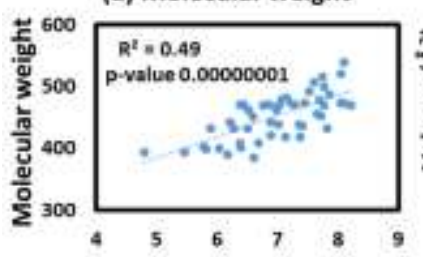

(e) WPSA
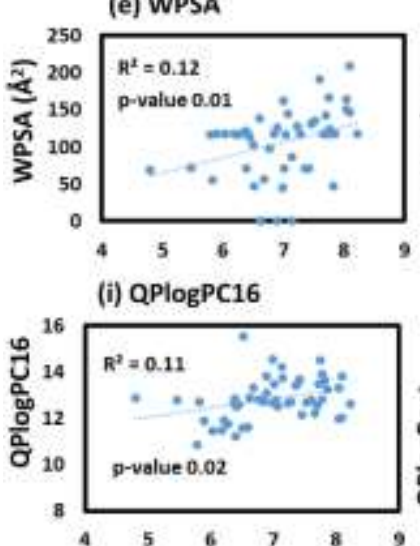

(b) Volume

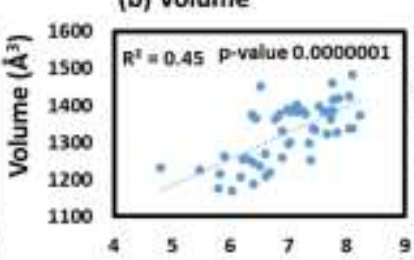

(f) accptHB

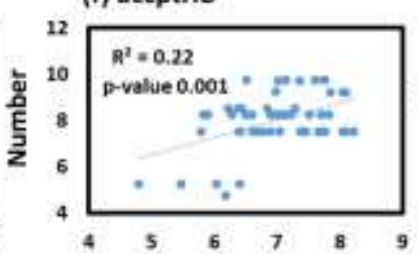

(j) QPlogPoct

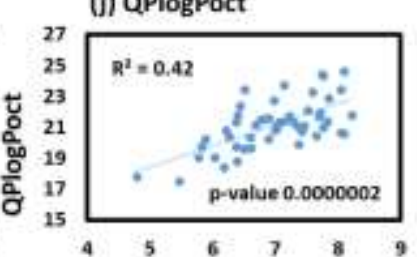

(c) SASA

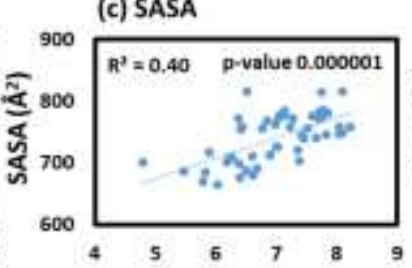

(g) glob
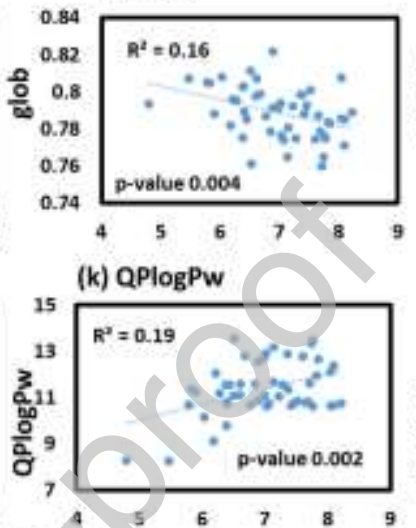

(d) FOSA

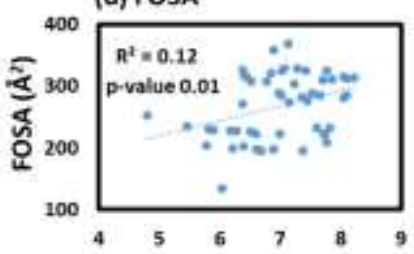

(h) QPpoirz

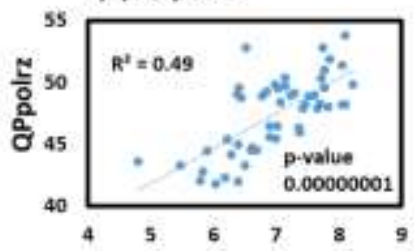

(i) CIQPlogs

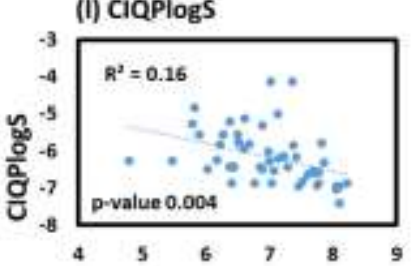

Fig. 4 Correlation between the $\mathrm{pIC}_{50}$ values and the physicochemical features of the dataset compounds calculated using the MMGBSA poses at site 4 (for SP poses at $0 \AA$ flexibilities). Correlation between the $\mathrm{pIC}_{50}$ with: (a) Molecular weight of GSM. (b) Volume of GSM. (c) Total solvent-accessible surface area (SASA). (d) Hydrophobic surface area (FOSA). (e) Weakly polar surface area (WPSA). (f) Number of hydrogen bond acceptors (accptHB). (g) Globular shape (glob). (h) Polarizability (QPpolrz). (i) Hexadecane-gas partition coefficient (QPlogPC16). (j) Octanol-gas partition coefficient (QPlogPoct). (k) Water-gas partition coefficient (QPlogPw). (l) Conformation-independent aqueous solubility (CIQPlogS).

Of these properties, the strongest correlations $\left(\mathrm{R}^{2}>0.4\right)$ all relate to molecular size, hydrophobicity, and polarizability. Remarkably, these properties are even better descriptors of potency than via their contribution to the binding affinity alone (as estimated by MMGBSA). Thus, our results suggest that GSMs work in two ways: The binding affinity itself contributes stability to the ternary enzyme-modulator-substrate complex and reduces $\mathrm{K}_{\mathrm{m}}$ to increase turnover $\left(\mathrm{k}_{\mathrm{cat}} / \mathrm{K}_{\mathrm{m}}\right)$ and cleavage to shorter $\mathrm{A} \beta$. At the same time, the size, hydrophobicity, and polarizability indicate an additional role of conformation state, probably via the relative free energies of the more compact semi-open and the open PS1 states. The GSMs, by hydrophobic packing and polarizable 
interactions, thus plausibly increase the relative stability of the innocent semi-open conformation over the open state that produces imprecise cleavage and longer $\mathrm{A} \beta$, as implied by the FIST model (Dehury et al., 2019b; Somavarapu and Kepp, 2017, 2016; Tang et al., 2019, 2018).

(a)

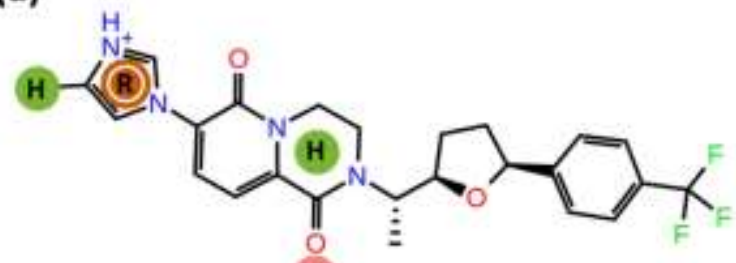

(A)

(c)

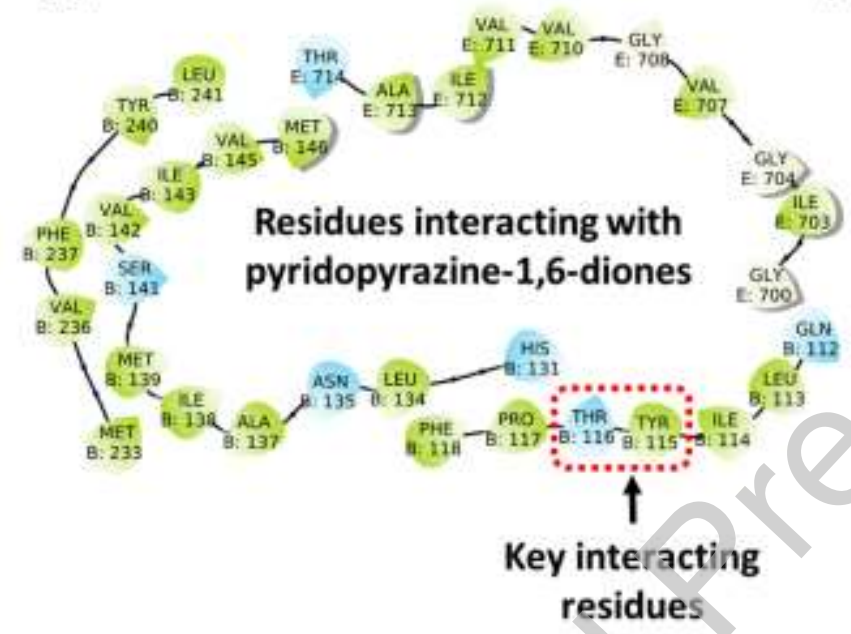

(b)

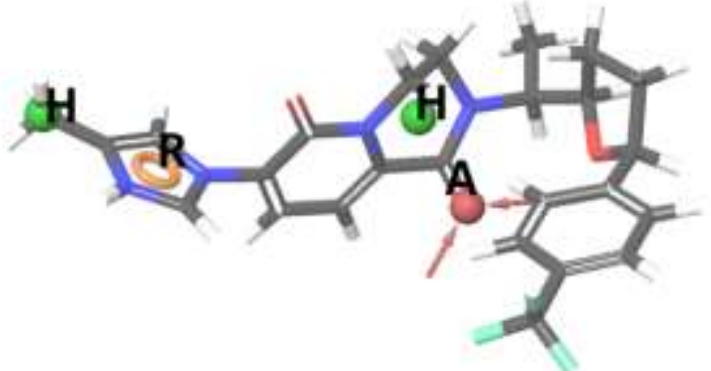

(d)

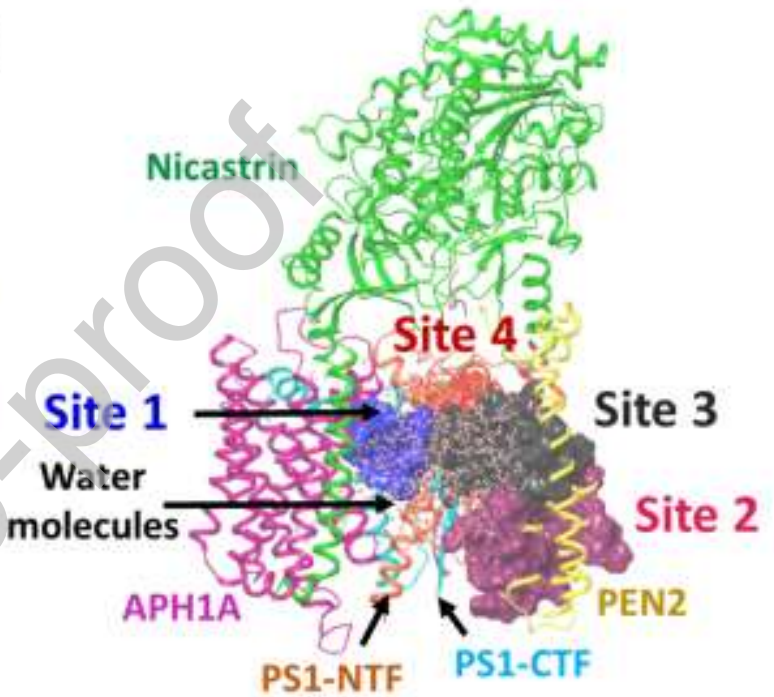

Fig. 5 Common pharmacophore hypothesis developed using the binding poses of the MMGBSA poses (SP, $0 \AA$ flexibility) at site 4 , residues interacting with the dataset compounds, and the solvent accessibility of the binding sites. Pharmacophoric features displayed on 2D-structure (a) and 3D-structure (b) of the best fit compound 78 (78-15 variant; J. Med Chem., 2016, 59, 7389). (c) Site 4 residues forming interactions with the 122 dataset compounds. (d) Analysis of site solvent accessibility. Water molecules are shown as wires and the binding sites as surfaces.

\subsection{Common pharmacophore model and interactions for the GSMs}

We wanted to take the structure-activity relationships a step further, by including more directly the 3-dimensional binding sites that we identified in the first part of this study. To this aim, the 122 ligand poses generated by MMGBSA at site 4 were aligned using Phase. The high-scoring fourpoint hypothesis matching the highest number of ligands was then selected (Fig. 5). AHHR 
hypothesis, which contained one hydrogen bond acceptor (A), two hydrophobic $(\mathrm{H})$ and one aromatic (R) features, matched 42 ligand states (neutral and ionization, Table S1) of the 28 dataset compounds. The hydrogen bond acceptor (A) feature was formed by the carboxyl oxygen, two hydrophobic interactions $(\mathrm{H})$ were constituted by the six-membered heterocyclic ring and methyl groups attached to imidazole, and one aromatic interaction was formed by the imidazole ring. The nature of the best common pharmacophore model thus confirms the importance of the specific shape and hydrophobic properties of the compounds within the actual binding cavity.

We further analyzed the protein-ligand interactions of all 122 dataset ligands within site 4 . The pyridopyrazine-1,6-diones mainly interacted with hydrophobic residues (green) and some polar residues (cyan) as summarized in Fig. 5c and Table S9. The main interactions were formed with PS1-NTF residues, notably Tyr115 and Thr116. The hydrophobic Tyr115 mainly formed $\pi-\pi$ interactions with the pyridopyrazine ring and in a few cases with the imidazole ring. This residue also formed $\pi$-cation interactions between its phenyl ring and the positively charged nitrogen atom on imidazole or other substituted groups (such as 4-azaindole) in the protonated state. This interaction increases the binding affinity of the protonated ligands. The low-activity compounds 27 $\left(\mathrm{IC}_{50}=920 \mathrm{nM}\right)$ and $28\left(\mathrm{IC}_{50}=400 \mathrm{nM}\right)$ have a hydroxyl group on the pyridopyrazine ring, hydrogen bonding to Tyr115. Thr116 donated a hydrogen bond to one of the two oxygen atoms of the pyridopyrazine rings. One of these oxygens was identified as an important hydrogen bond acceptor in the pharmacophore analysis, in support of this conclusion (A; Fig. 5a and 5b). In addition, the residue Ile114 accepted a hydrogen bond from the nitrogen of the indole, 4-azaindole or similar substitutions in some of the ligands, and Phe237 also formed $\pi$ - $\pi$ interactions with the imidazole ring in some cases. Some residues of C83 also interacted actively with the ligands (Fig. 5c), mostly Thr714 with a tendency to accept a hydrogen bond from the protonated nitrogen atom of the azaindole substituents.

We also analyzed the solvent accessibility of the four binding sites in the membrane environment. Some of the transmembrane binding sites may never be accessible by the ligands due to the compact membrane surrounding the protein. To analyze the solvent accessibility of the predicted binding sites, we built a 1-palmitoyl-2-oleoyl-sn-glycero-3-phosphocholine (POPC) bilayer membrane around 6IYC using CHARMMGUI(Jo et al., 2008) along with the water molecules in the pore-forming transmembrane regions of the protein (Fig. 5d). We found that the sites 1 and 3 were highly solvent-accessible, whereas the sites 2 and 4 were less water accessible. We analyzed a static protein-membrane-water complex with some solvent accessibility. However, $\gamma$-secretase is highly flexible and therefore, all these sites are expected to be accessible by the solvent during protein conformational changes. 


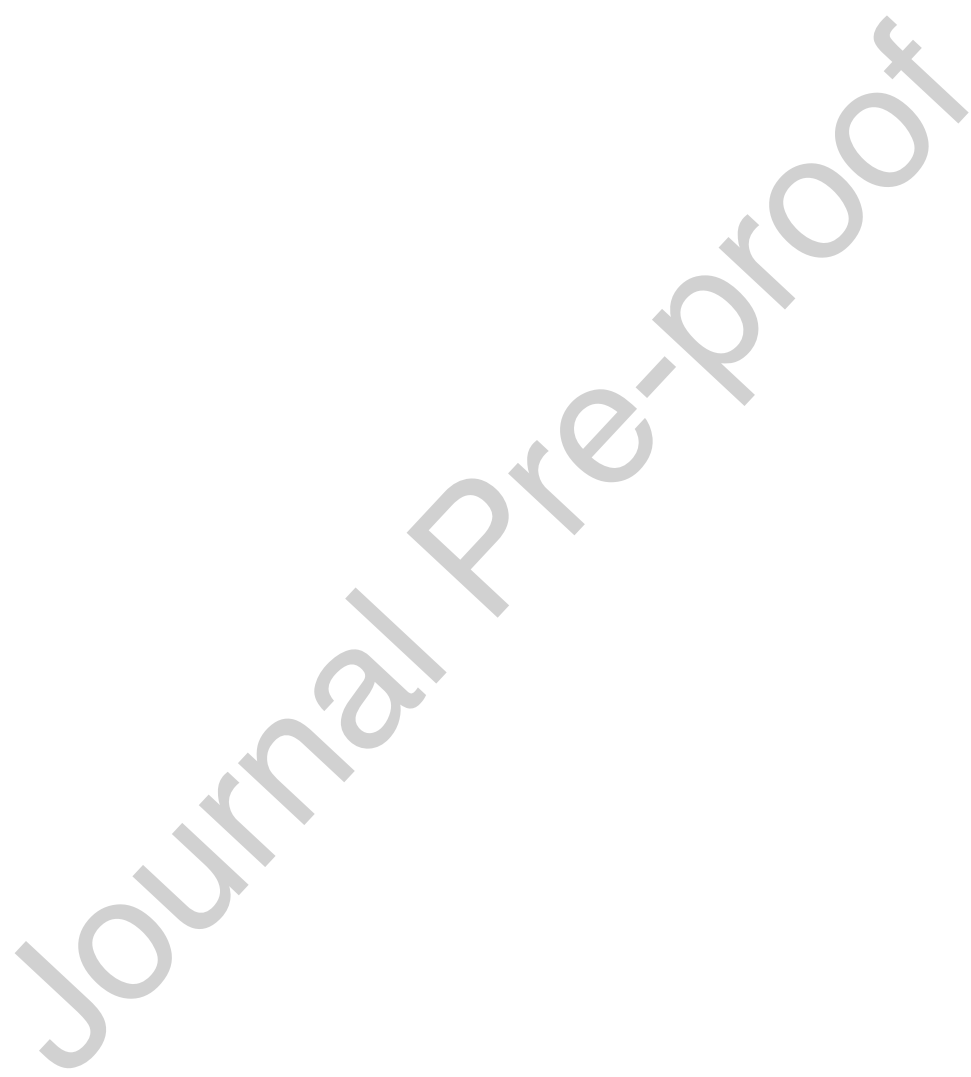




\section{Conclusions}

Using a diverse range of molecular modelling techniques, we identified four potential binding sites for pyridopyrazine-1,6-dione GSMs binding to the transmembrane domains of $\gamma$-secretase. These compounds have previously been reported to bind to the PSI-NTF (Pettersson et al., 2015a). We demonstrated that these compounds bind to a specific site (site 4) formed between PS1-TM2, PS1TM5 and the APP-C83-TM (Fig. 1). The experimental activity data correlate significantly (95\% confidence, linear regression) with MMGBSA-affinities only for this site, not the three other sites that were identified.

The binding of the GSMs at the interface between PS1-NTF and the substrate indicates how GSMs may strengthen the ternary enzyme-substrate modulator complex, thus preventing early release of the substrate from $\gamma$-secretase complex and thus increasing trimming to shorter $\mathrm{A} \beta$ peptides. The possibility that other compound classes of GSMs bind to other of the four identified sites may not be ignored (Fig. 1), since different chemical properties may lead to different preferences for the sites. Our analysis of all possible stereoisomers and specific protonation states that may be active at physiological $\mathrm{pH}$ show that charged protonated GSMs may in some cases display higher affinities than the neutral states, because of $\pi$-cation interaction with Tyr115 of PS1NTF in site 4.

We found that the MMGBSA-estimated binding affinities correlated significantly with the size, shape, hydrophobicity, and polarizability, largely following general size-affinity expectations for small to moderate-sized compounds (Kuntz et al., 1999). In agreement with the extended, solventexposed nature of site 4, an extended shape of the GSM was also found to be favourable.

Surprisingly and very promisingly, structure-activity relation studies showed that the $\mathrm{pIC}_{50}$ of these compounds is largely described $\left(\mathrm{R}^{2}>0.4\right.$ for all of these) by the molecular size, hydrophobicity, and polarizability. Remarkably, we found that these properties are even better descriptors of potency than via their contribution to the binding affinity alone (as estimated by MMGBSA).

From our study, we conclude that we have identified the primary modulator binding site in $\gamma$ secretase for this important class of compounds, as well as strong descriptors of GSM potency. Our results suggest that GSMs work in two ways: The binding affinity itself contributes stability to the ternary enzyme-modulator-substrate complex and reduces $\mathrm{K}_{\mathrm{m}}$ to increase turnover $\left(\mathrm{k}_{\mathrm{cat}} / \mathrm{K}_{\mathrm{m}}\right)$ and cleavage to shorter $\mathrm{A} \beta$. At the same time, the size, hydrophobicity, and polarizability indicate an additional contribution that relates to a conformation change, which we have previously argued is the relative free energies of the more compact semi-open and the open PS1 states. The GSMs, by 
hydrophobic packing and polarizable interactions, are proposed to increase the relative stability of the innocent semi-open conformation over the open state that produces imprecise cleavage and longer $A \beta$. Both of these mechanisms fully in accord with the FIST model of $\gamma$-secretase function (Dehury et al., 2019b; Somavarapu and Kepp, 2017, 2016; Tang et al., 2019, 2018).

\section{Funding}

The work is supported by the Danish Council for Independent Research | Natural Sciences (DFF), grant case 7016-00079B.

\section{Supporting information}

The supporting information contains dataset compounds, physiochemical analysis, predicted binding sites, plots for the SP and XP docking and MMGBSA computations, and stereoisomers analysis.

\section{Author contributions}

RM and KPK conceptualized and planned the work. RM performed all calculations. RM and KPK analyzed data. RK wrote the original draft, and KPK wrote the final paper together.

\section{Conflicts of interest}

The authors declare that they have no conflicts of interest associated with this work.

\section{Acknowledgements}

The Danish Council for Independent Research | Natural Sciences (DFF), grant case 7016-00079B, is acknowledged for supporting this work. We acknowledge the use and help from the DTU HighPerformance Computing (HPC) facility for the computations carried out in this work.

\section{Availability of data and material}

Not applicable 


\section{Credit Author statement}

RM and KPK conceptualized and planned the work. RM performed all calculations. RM and KPK analyzed data. RK wrote the original draft, and KPK wrote the final paper together. 


\section{References}

Augustinack, J.C., Schneider, A., Mandelkow, E.M., Hyman, B.T., 2002. Specific tau phosphorylation sites correlate with severity of neuronal cytopathology in Alzheimer's disease. Acta Neuropathol 103, 26-35. https://doi.org/10.1007/s004010100423

Avila, J., 2006. Tau phosphorylation and aggregation in Alzheimer's disease pathology. FEBS Lett 580, 2922-2927. https://doi.org/10.1016/j.febslet.2006.02.067

Bezprozvanny, I., Mattson, M.P., 2008. Neuronal calcium mishandling and the pathogenesis of Alzheimer's disease. Trends Neurosci 31, 454-463.

Blennow, K., de Leon, M.J., Zetterberg, H., 2015. Alzheimer's disease. Lancet 368, 387-403. https://doi.org/10.1016/S0140-6736(06)69113-7

Bolduc, D.M., Montagna, D.R., Seghers, M.C., Wolfe, M.S., Selkoe, D.J., 2016. The amyloid-beta forming tripeptide cleavage mechanism of $\gamma$-Secretase. Elife 5, e17578. https://doi.org/10.7554/eLife.17578

Bramblett, G.T., Goedert, M., Jakes, R., Merrick, S.E., Trojanowski, J.Q., Lee, V.M.Y., 1993. Abnormal tau phosphorylation at Ser396 in alzheimer's disease recapitulates development and contributes to reduced microtubule binding. Neuron 10, 1089-1099. https://doi.org/10.1016/0896-6273(93)90057-X

Bursavich, M.G., Harrison, B.A., Blain, J.F., 2016. Gamma secretase modulators: New Alzheimer's drugs on the horizon? J Med Chem 59, 7389-7409. https://doi.org/10.1021/acs.jmedchem.5b01960

Cai, T., Yonaga, M., Tomita, T., 2017. Activation of $\gamma$-secretase trimming activity by topological changes of transmembrane domain 1 of presenilin 1. J Neurosci 37, 12272-12280. https://doi.org/10.1523/JNEUROSCI.1628-17.2017

Carreiras, M., Mendes, E., Perry, M., Francisco, A., Marco-Contelles, J., 2013. The Multifactorial Nature of Alzheimer's Disease for Developing Potential Therapeutics. Curr Top Med Chem 13, 1745-1770. https://doi.org/10.2174/15680266113139990135

Crump, C.J., Fish, B.A., Castro, S. V., Chau, D.M., Gertsik, N., Ahn, K., Stiff, C., Pozdnyakov, N., Bales, K.R., Johnson, D.S., Li, Y.M., 2011. Piperidine acetic acid based $\gamma$-secretase modulators directly bind to presenilin-1. ACS Chem Neurosci 2(12), 705-710. https://doi.org/10.1021/cn200098p 
Crump, C.J., Johnson, D.S., Li, Y.M., 2013. Development and mechanism of $\gamma$-secretase modulators for Alzheimer's disease. Biochemistry 52, 3197-3216. https://doi.org/10.1021/bi400377p

Dartigues, J.F., 2009. Alzheimer's disease: a global challenge for the 21st century. Lancet Neurol 8, 1082-1083. https://doi.org/10.1016/s1474-4422(09)70298-4

De Strooper, B., Chávez Gutiérrez, L., 2015. Learning by Failing: Ideas and Concepts to Tackle $\gamma$ Secretases in Alzheimer's Disease and Beyond. Annu Rev Pharmacol Toxicol 55, 419-437. https://doi.org/10.1146/annurev-pharmtox-010814-124309

De Strooper, B., Iwatsubo, T., Wolfe, M.S., 2012. Presenilins and $\gamma$-secretase: structure, function, and role in Alzheimer Disease. Cold Spring Harb Perspect Med 2, a006304. https://doi.org/10.1101/cshperspect.a006304

Dehury, B., Tang, N., Blundell, T.L., Kepp, K.P., 2019a. Structure and dynamics of $\gamma$-secretase with presenilin 2 compared to presenilin 1. RSC Adv 9, 20901-20916.

Dehury, B., Tang, N., Kepp, K.P., 2019b. Molecular dynamics of C99-bound $\gamma$-secretase reveal two binding modes with distinct compactness, stability, and active-site retention: Implications for A $\beta$ production. Biochem J 476, 1173-1189.

Dixon, S.L., Smondyrev, A.M., Knoll, E.H., Rao, S.N., Shaw, D.E., Friesner, R.A., 2006. PHASE: A new engine for pharmacophore perception, 3D QSAR model development, and 3D database screening: 1. Methodology and preliminary results. J Comput Aided Mol Des 20, 647-671. https://doi.org/10.1007/s10822-006-9087-6

Duering, M., Grimm, M.O.W., Grimm, H.S., Schroder, J., Hartmann, T., 2005. Mean age of onset in familial Alzheimer's disease is determined by amyloid beta 42. Neurobiol Aging 26, 785788. https://doi.org/10.1016/j.neurobiolaging.2004.08.002

Ebke, A., Luebbers, T., Fukumori, A., Shirotani, K., Haass, C., Baumann, K., Steiner, H., 2011. Novel $\gamma$-secretase enzyme modulators directly target presenilin protein. J Biol Chem 286(43), 37181-37186. https://doi.org/10.1074/jbc.C111.276972

Extance, A., 2010. Alzheimer's failure raises questions about disease-modifying strategies. Nat Rev Drug Discov 9, 749-751. https://doi.org/10.1038/nrd3288

Friesner, R.A., Banks, J.L., Murphy, R.B., Halgren, T.A., Klicic, J.J., Mainz, D.T., Repasky, M.P., Knoll, E.H., Shelley, M., Perry, J.K., Shaw, D.E., Francis, P., Shenkin, P.S., 2004. Glide: A 
New Approach for Rapid, Accurate Docking and Scoring. 1. Method and Assessment of Docking Accuracy. J Med Chem 47, 1739-1749. https://doi.org/10.1021/jm0306430

Friesner, R.A., Murphy, R.B., Repasky, M.P., Frye, L.L., Greenwood, J.R., Halgren, T.A., Sanschagrin, P.C., Mainz, D.T., 2006. Extra precision glide: docking and scoring incorporating a model of hydrophobic enclosure for protein-ligand complexes. J Med Chem 49, 6177-6196. https://doi.org/10.1021/jm051256o

Fukumori, A., Fluhrer, R., Steiner, H., Haass, C., 2010. Three-amino acid spacing of presenilin endoproteolysis suggests a general stepwise cleavage of gamma-secretase-mediated intramembrane proteolysis. J Neurosci 30, 7853-7862. https://doi.org/10.1523/JNEUROSCI.1443-10.2010

Golde, T.E., Estus, S., Younkin, L.H., Selkoe, D.J., Younkin, S.G., 1992. Processing of the amyloid protein precursor to potentially amyloidogenic derivatives. Science (80- ) 255 (5045), 728730. https://doi.org/10.1126/science. 1738847

Golde, T.E., Koo, E.H., Felsenstein, K.M., Osborne, B.A., Miele, L., 2013. $\gamma$-Secretase inhibitors and modulators. Biochim Biophys Acta - Biomembr 1828 (2013, 2898-2907. https://doi.org/10.1016/j.bbamem.2013.06.005

Haapasalo, A., Kovacs, D.M., 2011. The many substrates of presenilin/ $\gamma$-secretase. J Alzheimer's Dis. https://doi.org/10.3233/JAD-2011-101065

Halgren, T.A., 2009. Identifying and characterizing binding sites and assessing druggability. J Chem Inf Model 49, 377-389.

Halgren, T.A., Murphy, R.B., Friesner, R.A., Beard, H.S., Frye, L.L., Pollard, W.T., Banks, J.L., 2004. Glide: A New Approach for Rapid, Accurate Docking and Scoring. 2. Enrichment Factors in Database Screening. J Med Chem 47, 1750-1759. https://doi.org/10.1021/jm030644s

Hall, V.J., 2018. No new drugs for Alzheimer's disease in 15 years.

Hardy, J.A., Higgins, G.A., 1992. Alzheimer's disease: the amyloid cascade hypothesis. Science (80- ) 256, 184-185.

Hassing, L.B., Dahl, A.K., Thorvaldsson, V., Berg, S., Gatz, M., Pedersen, N.L., Johansson, B., 2009. Overweight in midlife and risk of dementia: a 40-year follow-up study. Int J Obesity, Int J Obes, Int J Obes, Int J Obesity, Int J Obes Relat Metab Disord Int J Obes (lond), Int J Obes 
Relat Metab Disord 33, 893-898. https://doi.org/10.1038/ijo.2009.104

Holtzman, D.M., Morris, J.C., Goate, A.M., 2011. Alzheimer's disease: the challenge of the second century. Sci Transl Med 3, 77sr1. https://doi.org/10.1126/scitranslmed.3002369

Hopkins, C.R., 2011. ACS chemical neuroscience molecule spotlight on ELND006: Another $\gamma-$ secretase inhibitor fails in the clinic. ACS Chem Neurosci 2, 279-280.

https://doi.org/10.1021/cn2000469

Imbimbo, B.P., Giardina, G.A.M., 2011. gamma-secretase inhibitors and modulators for the treatment of Alzheimer's disease: disappointments and hopes. Curr Top Med Chem 11, 15551570.

Iqbal, K., Grundke-Iqbal, I., 2010. Alzheimer's disease, a multifactorial disorder seeking multitherapies. Alzheimer's Dement. https://doi.org/10.1016/j.jalz.2010.04.006

Isoo, N., Sato, C., Miyashita, H., Shinohara, M., Takasugi, N., Morohashi, Y., Tsuji, S., Tomita, T., Iwatsubo, T., 2007. A $\beta 42$ overproduction associated with structural changes in the catalytic pore of $\gamma$-secretase: Common effects of Pen-2 N-terminal elongation and fenofibrate. J Biol Chem 282(17), 12388-12396. https://doi.org/10.1074/jbc.M611549200

Jo, S., Kim, T., Iyer, V.G., Im, W., 2008. CHARMM-GUI: A web-based graphical user interface for CHARMM. J Comput Chem 29, 1859-1865. https://doi.org/10.1002/jcc.20945

Johnson, D.S., Pettersson, M., 2017. $\gamma$-secretase modulators as A $\beta 42$-lowering pharmacological agents to treat Alzheimer's disease, in: Alzheimer's Disease II. Topics in Medicinal Chemistry. Springer, Cham, pp. 87-118. https://doi.org/10.1007/7355_2016_19

Jumpertz, T., Rennhack, A., Ness, J., Baches, S., Pietrzik, C.U., Bulic, B., Weggen, S., 2012. Presenilin is the molecular target of acidic $\gamma$-secretase modulators in living cells. PLoS One 7, e30484. https://doi.org/10.1371/journal.pone.0030484

Kepp, K.P., 2019. A quantitative model of human neurodegenerative diseases involving protein aggregation. Neurobiol Aging 80, 46-55.

https://doi.org/https://doi.org/10.1016/j.neurobiolaging.2019.04.001

Kepp, K.P., 2017. Ten Challenges of the Amyloid Hypothesis of Alzheimer's Disease. J

Alzheimer's Dis 55, 447-457. https://doi.org/10.3233/JAD-160550

Kepp, K.P., 2016. Alzheimer's disease due to loss of function: A new synthesis of the available data. Prog Neurobiol 143, 36-60. https://doi.org/10.1016/j.pneurobio.2016.06.004 
Kepp, K.P., 2012. Bioinorganic chemistry of Alzheimer's disease. Chem Rev.

https://doi.org/10.1021/cr300009x

Kepp, K.P., Squitti, R., 2019. Copper imbalance in Alzheimer's disease: Convergence of the chemistry and the clinic. Coord Chem Rev 397, 168-187.

https://doi.org/https://doi.org/10.1016/j.ccr.2019.06.018

Khachaturian, Z.S., 1987. Hypothesis on the regulation of cytosol calcium concentration and the aging brain. Neurobiol Aging 8, 345-346.

Kounnas, M.Z., Danks, A.M., Cheng, S., Tyree, C., Ackerman, E., Zhang, X., Ahn, K., Nguyen, P., Comer, D., Mao, L., Yu, C., Pleynet, D., Digregorio, P.J., Velicelebi, G., Stauderman, K.A., Comer, W.T., Mobley, W.C., Li, Y.M., Sisodia, S.S., Tanzi, R.E., Wagner, S.L., 2010. Modulation of $\gamma$-Secretase Reduces $\beta$-Amyloid Deposition in a Transgenic Mouse Model of Alzheimer's Disease. Neuron 67(5), 769-780. https://doi.org/10.1016/j.neuron.2010.08.018

Kozakov, D., Grove, L.E., Hall, D.R., Bohnuud, T., Mottarella, S.E., Luo, L., Xia, B., Beglov, D., Vajda, S., 2015. The FTMap family of web servers for determining and characterizing ligandbinding hot spots of proteins. Nat Protoc 10(5), 733-755. https://doi.org/10.1038/nprot.2015.043

Kumar-Singh, S., Theuns, J., Van Broeck, B., Pirici, D., Vennekens, K., 2006. Mean age-of-onset of familial alzheimer disease caused by presenilin mutations correlates with both increased A $\beta 42$ and decreased A $\beta 40$. Hum Mutat 27, 686-695.

Kuntz, I.D., Chen, K., Sharp, K.A., Kollman, P.A., 1999. The maximal affinity of ligands. Proc Natl Acad Sci 96, 9997-10002. https://doi.org/10.1073/pnas.96.18.9997

LigPrep (No. Schrödinger Release 2018-4:), 2018. . Schrödinger, LLC, New York, NY, 2018.

Lomize, M.A., Pogozheva, I.D., Joo, H., Mosberg, H.I., Lomize, A.L., 2012. OPM database and PPM web server: Resources for positioning of proteins in membranes. Nucleic Acids Res 40, D370-D376. https://doi.org/10.1093/nar/gkr703

Masters, C.L., Gajdusek, D.C., Gibbs, C.J.J., 1981. The familial occurrence of Creutzfeldt-Jakob disease and Alzheimer's disease. Brain 104, 535-558.

Mehra, R., Dehury, B., Kepp, K.P., 2020. Cryo-temperature effects on membrane protein structure and dynamics. Phys Chem Chem Phys in press., DOI: 10.1039/C9CP06723J.

Mehra, R., Kepp, K.P., 2019. Computational analysis of Alzheimer-causing mutations in amyloid 
precursor protein and presenilin 1. Arch Biochem Biophys 678, 108168.

https://doi.org/https://doi.org/10.1016/j.abb.2019.108168

Mehra, R., Meyer, A.S.A.S., Kepp, K.P.K.P., 2018a. Molecular dynamics derived life times of active substrate binding poses explain KM of laccase mutants. RSC Adv 8, 36915-36926. https://doi.org/10.1039/c8ra07138a

Mehra, R., Muschiol, J., Meyer, A.S.A.S., Kepp, K.P.K.P., 2018b. A structural-chemical explanation of fungal laccase activity. Sci Rep 8, 17285. https://doi.org/10.1038/s41598-018$35633-8$

Mehra, R., Sharma, R., Khan, I.A.I.A., Nargotra, A., 2015. Identification and optimization of Escherichia coli GlmU inhibitors: An in silico approach with validation thereof. Eur J Med Chem 92, 78-90. https://doi.org/10.1016/j.ejmech.2014.12.030

Morris, J.K., Honea, R.A., Vidoni, E.D., Swerdlow, R.H., Burns, J.M., 2014. Is Alzheimer's disease a systemic disease? Biochim Biophys Acta - Mol Basis Dis. https://doi.org/10.1016/j.bbadis.2014.04.012

Nichols, E., Szoeke, C.E.I., Vollset, S.E., Abbasi,N., Abd-Allah, F., Abdela, J., Aichour, M.T.E., Akinyemi, R.O., Alahdab, F., Asgedom, S.W., Awasthi, A., Barker-Collo, S.L., Baune, B.T., Béjot, Y., Belachew, A.B., Bennett, D.A., Biadgo, B., Bijani, A., Bin Sayeed, M.S., Brayne, C., Carpenter, D.O., Carvalho, F., Catalá-López, F., Cerin, E., Choi, J.Y.J., Dang, A.K., Degefa, M.G., Djalalinia, S., Dubey, M., Duken, E.E., Edvardsson, D., Endres, M., Eskandarieh, S., Faro, A., Farzadfar, F., Fereshtehnejad, S.M., Fernandes, E., Filip, I., Fischer, F., Gebre, A.K., Geremew, D., Ghasemi-Kasman, M., Gnedovskaya, E. V., Gupta, R., Hachinski, V., Hagos, T.B., Hamidi, S., Hankey, G.J., Haro, J.M., Hay, S.I., Irvani, S.S.N., Jha, R.P., Jonas, J.B., Kalani, R., Karch, A., Kasaeian, A., Khader, Y.S., Khalil, I.A., Khan, E.A., Khanna, T., Khoja, T.A.M., Khubchandani, J., Kisa, A., Kissimova-Skarbek, K., Kivimäki, M., Koyanagi, A., Krohn, K.J., Logroscino, G., Lorkowski, S., Majdan, M., Malekzadeh, R., März, W., Massano, J., Mengistu, G., Meretoja, A., Mohammadi, M., Mohammadi-Khanaposhtani, M., Mokdad, A.H., Mondello, S., Moradi, G., Nagel, G., Naghavi, M., Naik, G., Nguyen, L.H., Nguyen, T.H., Nirayo, Y.L., Nixon, M.R., OforiAsenso, R., Ogbo, F.A., Olagunju, A.T., Owolabi, M.O., Panda-Jonas, S., Passos, V.M. d. A., Pereira, D.M., Pinilla-Monsalve, G.D., Piradov, M.A., Pond, C.D., Poustchi, H., Qorbani, M., Radfar, A., Reiner, R.C., Robinson, S.R., Roshandel, G., Rostami, A., Russ, T.C., Sachdev, P.S., Safari, H., Safiri, S., Sahathevan, R., Salimi, Y., Satpathy, M., Sawhney, M., Saylan, M., 
Sepanlou, S.G., Shafieesabet, A., Shaikh, M.A., Sahraian, M.A., Shigematsu, M., Shiri, R., Shiue, I., Silva, J.P., Smith, M., Sobhani, S., Stein, D.J., Tabarés-Seisdedos, R., TovaniPalone, M.R., Tran, B.X., Tran, T.T., Tsegay, A.T., Ullah, I., Venketasubramanian, N., Vlassov, V., Wang, Y.P., Weiss, J., Westerman, R., Wijeratne, T., Wyper, G.M.A., Yano, Y., Yimer, E.M., Yonemoto, N., Yousefifard, M., Zaidi, Z., Zare, Z., Vos, T., Feigin, V.L., Murray, C.J.L., 2019. Global, regional, and national burden of Alzheimer's disease and other dementias, 1990-2016: a systematic analysis for the Global Burden of Disease Study 2016. Lancet Neurol 18, 88-106. https://doi.org/10.1016/S1474-4422(18)30403-4

Oehlrich, D., Berthelot, D.J.-C., Gijsen, H.J.M., 2010. $\gamma$-Secretase Modulators as Potential Disease Modifying Anti-Alzheimer's Drugs. J Med Chem 54, 669-698.

https://doi.org/10.1021/jm101168r

Oehlrich, D., Berthelot, D.J.C., Gijsen, H.J.M., 2011. $\gamma$-Secretase modulators as potential disease modifying anti-Alzheimer's drugs. J Med Chem 54(3), 669-698. https://doi.org/10.1021/jm101168r

Ohki, Y., Higo, T., Uemura, K., Shimada, N., Osawa, S., Berezovska, O., Yokoshima, S., Fukuyama, T., Tomita, T., Iwatsubo, T., 2011. Phenylpiperidine-type $\gamma$-secretase modulators target the transmembrane domain 1 of presenilin 1. EMBO J 30(23), 4815-4824. https://doi.org/10.1038/emboj.2011.372

Petit, D., Hitzenberger, M., Lismont, S., Zoltowska, K.M., Ryan, N.S., Mercken, M., Bischoff, F., Zacharias, M., Chávez-Gutiérrez, L., 2019. Extracellular interface between APP and Nicastrin regulates A $\beta$ length and response to $\gamma$-secretase modulators. EMBO J 38, e101494. https://doi.org/10.15252/embj.2019101494

Pettersson, M., Johnson, D.S., Humphrey, J.M., Am Ende, C.W., Evrard, E., Efremov, I., Kauffman, G.W., Stepan, A.F., Stiff, C.M., Xie, L., Bales, K.R., Hajos-Korcsok, E., Murrey, H.E., Pustilnik, L.R., Steyn, S.J., Wood, K.M., Verhoest, P.R., 2015a. Discovery of indolederived pyridopyrazine-1,6-dione $\gamma$-secretase modulators that target presenilin. Bioorganic Med Chem Lett 25(4), 908-913. https://doi.org/10.1016/j.bmcl.2014.12.059

Pettersson, M., Johnson, D.S., Humphrey, J.M., Butler, T.W., Am Ende, C.W., Fish, B.A., Green, M.E., Kauffman, G.W., Mullins, P.B., O’Donnell, C.J., Stepan, A.F., Stiff, C.M., Subramanyam, C., Tran, T.P., Vetelino, B.C., Yang, E., Xie, L., Bales, K.R., Pustilnik, L.R., Steyn, S.J., Wood, K.M., Verhoest, P.R., 2015b. Design of pyridopyrazine-1,6-dione $\gamma$ secretase modulators that align potency, MDR efflux ratio, and metabolic stability. ACS Med 
Chem Lett 6(5), 596-601. https://doi.org/10.1021/acsmedchemlett.5b00070

Pettersson, M., Johnson, D.S., Subramanyam, C., Bales, K.R., Am Ende, C.W., Fish, B.A., Green, M.E., Kauffman, G.W., Mullins, P.B., Navaratnam, T., Sakya, S.M., Stiff, C.M., Tran, T.P., Xie, L., Zhang, L., Pustilnik, L.R., Vetelino, B.C., Wood, K.M., Pozdnyakov, N., Verhoest, P.R., O’Donnell, C.J., 2014. Design, synthesis, and pharmacological evaluation of a novel series of pyridopyrazine-1,6-dione $\gamma$-secretase modulators. J Med Chem 57(3), 1046-1062. https://doi.org/10.1021/jm401782h

Pozdnyakov, N., Murrey, H.E., Crump, C.J., Pettersson, M., Ballard, T.E., Am Ende, C.W., Ahn, K., Li, Y.M., Bales, K.R., Johnson, D.S., 2013. $\gamma$-secretase modulator (GSM) photoaffinity probes reveal distinct allosteric binding sites on presenilin. J Biol Chem 288(14), 9710-9720. https://doi.org/10.1074/jbc.M112.398602

Prime (No. Schrödinger Release 2018-4), 2018. . Schrödinger, LLC, New York, NY, 2018.

Prince, M., Bryce, R., Albanese, E., Wimo, A., Ribeiro, W., Ferri, C.P., 2013. The global prevalence of dementia: A systematic review and metaanalysis. Alzheimer's Dement 9, 63-75. https://doi.org/10.1016/j.jalz.2012.11.007

Prince, M., Comas-Herrera, A., Knapp, M., Guerchet, M., Karagiannidou, M., 2016. World Alzheimer Report 2016 Improving healthcare for people living with dementia. Coverage, Quality and costs now and in the future. Alzheimer's Dis Int 1-140.

Protein Preparation Wizard, 2018. . Schrödinger, LLC, New York, NY, 2018.

QikProp (No. Schrödinger Release 2018-4:), 2018. . Schrödinger, LLC, New York, NY.

Rastelli, G., Del Rio, A., Degliesposti, G., Sgobba, M., 2010. Fast and accurate predictions of binding free energies using MM-PBSA and MM-GBSA. J Comput Chem 31(4), 797-810. https://doi.org/10.1002/jcc.21372

Razay, G., Vreugdenhil, A., Wilcock, G., 2006. Obesity, abdominal obesity and Alzheimer disease. Dement Geriatr Cogn Disord Dement Geriatr Cogn Disord, Dement G C, Dement Geriatr Cogn, Dement Geriatr Cogn Disord, Dement Geriatr Cogn Disord 22, 173-176. https://doi.org/10.1159/000094586

Roos, K., Wu, C., Damm, W., Reboul, M., Stevenson, J.M., Lu, C., Dahlgren, M.K., Mondal, S., Chen, W., Wang, L., 2019. OPLS3e: Extending force field coverage for drug-like small molecules. J Chem Theory Comput 15, 1863-1874. 
Rynearson, Kevin D, Buckle, R.N., Barnes, K.D., Herr, R.J., Mayhew, N.J., Paquette, W.D., Sakwa, S.A., Nguyen, P.D., Johnson, G., Tanzi, R.E., Wagner, S.L., 2016. Design and synthesis of aminothiazole modulators of the gamma-secretase enzyme. Bioorg Med Chem Lett 26, 39283937. https://doi.org/http://dx.doi.org/10.1016/j.bmcl.2016.07.011

Rynearson, Kevin D., Tanzi, R.E., Wagner, S.L., 2016. Discovery of potent gamma secretase modulators for the treatment of Alzheimer's disease, in: Translational Neuroscience: Fundamental Approaches for Neurological Disorders. Springer, Boston, MA, pp. 359-368. https://doi.org/10.1007/978-1-4899-7654-3_19

Sambamurti, K., Greig, N.H., Utsuki, T., Barnwell, E.L., Sharma, E., Mazell, C., Bhat, N.R., Kindy, M.S., Lahiri, D.K., Pappolla, M.A., 2011. Targets for AD treatment: Conflicting messages from $\gamma$-secretase inhibitors. J Neurochem 117(3), 359-374. https://doi.org/10.1111/j.14714159.2011.07213.x

Selkoe, D.J., Hardy, J., 2016. The amyloid hypothesis of Alzheimer's disease at 25 years. EMBO Mol Med 8. https://doi.org/10.15252/emmm.201606210

Shen, J., Kelleher, R.J., 2007. The presenilin hypothesis of Alzheimer's disease: evidence for a lossof-function pathogenic mechanism. Proc Natl Acad Sci U S A 104, 403-409. https://doi.org/10.1073/pnas.0608332104

Somavarapu, A.K., Kepp, K.P., 2017. Membrane Dynamics of $\gamma$-Secretase Provides a Molecular Basis for $\beta$-Amyloid Binding and Processing. ACS Chem Neurosci 8, 2424-2436.

Somavarapu, A.K., Kepp, K.P., 2016. Loss of stability and hydrophobicity of presenilin 1 mutations causing Alzheimer's Disease. J Neurochem 137, 101-111.

Steiner, H., Fukumori, A., Tagami, S., Okochi, M., 2018. Making the final cut: pathogenic amyloid$\beta$ peptide generation by $\gamma$-secretase. Cell Stress 2, 292-310. https://doi.org/10.15698/cst2018.11.162

Sun, L., Zhou, R., Yang, G., Shi, Y., 2017. Analysis of 138 pathogenic mutations in presenilin-1 on the in vitro production of $A \beta 42$ and $A \beta 40$ peptides by $\gamma$-secretase. Proc Natl Acad Sci U S A 114, E476-E485. https://doi.org/10.1073/pnas.1618657114

Takami, M., Nagashima, Y., Sano, Y., Ishihara, S., Morishima-Kawashima, M., Funamoto, S., Ihara, Y., 2009. $\gamma$-Secretase: successive tripeptide and tetrapeptide release from the transmembrane domain of $\beta$-carboxyl terminal fragment. J Neurosci 29, 13042-13052. https://doi.org/10.1523/JNEUROSCI.2362-09.2009 
Takeo, K., Tanimura, S., Shinoda, T., Osawa, S., Zahariev, I.K., Takegami, N., Ishizuka-Katsura, Y., Shinya, N., Takagi-Niidome, S., Tominaga, A., Ohsawa, N., Kimura-Someya, T., Shirouzu, M., Yokoshima, S., Yokoyama, S., Fukuyama, T., Tomita, T., Iwatsubo, T., 2014. Allosteric regulation of $\gamma$-secretase activity by a phenylimidazole-type $\gamma$-secretase modulator. Proc Natl Acad Sci 111, 10544-10549. https://doi.org/10.1073/pnas.1402171111

Tang, N., Dehury, B., Kepp, K.P., 2019. Computing the Pathogenicity of Alzheimer's Disease Presenilin 1 Mutations. J Chem Inf Model 59, 858-870. https://doi.org/10.1021/acs.jcim.8b00896

Tang, N., Kepp, K.P., 2018. A $\beta 42 / A \beta 40$ ratios of presenilin 1 mutations correlate with clinical onset of Alzheimer's disease. J Alzheimer's Dis 66, 939-945.

Tang, N., Somavarapu, A.K., Kepp, K.P., 2018. Molecular Recipe for $\gamma$-Secretase Modulation from Computational Analysis of 60 Active Compounds. ACS Omega 3, 18078-18088. https://doi.org/10.1021/acsomega.8b02196

Tanzi, R.E., Bertram, L., 2005. Twenty years of the Alzheimer's disease amyloid hypothesis: A genetic perspective. Cell. https://doi.org/10.1016/j.cell.2005.02.008

Tate, B., McKee, T.D., Loureiro, R.M.B., Dumin, J.A., Xia, W., Pojasek, K., Austin, W.F., Fuller, N.O., Hubbs, J.L., Shen, R., Jonker, J., Ives, J., Bronk, B.S., 2012. Modulation of gammasecretase for the treatment of alzheimer's disease. Int J Alzheimers Dis 2012. https://doi.org/10.1155/2012/210756

Tiwari, M.K., Kepp, K.P., 2016. $\beta$-Amyloid pathogenesis: Chemical properties versus cellular levels. Alzheimer's Dement. https://doi.org/10.1016/j.jalz.2015.06.1895

Uemura, K., Farner, K.C., Hashimoto, T., Nasser-Ghodsi, N., Wolfe, M.S., Koo, E.H., Hyman, B.T., Berezovska, O., 2010. Substrate docking to $\gamma$-secretase allows access of $\gamma$-secretase modulators to an allosteric site. Nat Commun 1, 130. https://doi.org/10.1038/ncomms 1129

Uemura, K., Lill, C.M., Li, X., Peters, J.A., Ivanov, A., Fan, Z., DeStrooper, B., Bacskai, B.J., Hyman, B.T., Berezovska, O., 2009. Allosteric modulation of PS1/ $\gamma$-secretase conformation correlates with amyloid $\beta 42 / 40$ ratio. PLoS One 4, e7893. https://doi.org/10.1371/journal.pone.0007893

Vilalta, A., Brown, G.C., 2018. Neurophagy, the phagocytosis of live neurons and synapses by glia, contributes to brain development and disease. FEBS J 285, 3566-3575. https://doi.org/10.1111/febs.14323 
Watanabe, N., Tomita, T., Sato, C., Kitamura, T., Morohashi, Y., Iwatsubo, T., 2005. Pen-2 is incorporated into the $\gamma$-secretase complex through binding to transmembrane domain 4 of presenilin 1. J Biol Chem 280(51), 41967-41975. https://doi.org/10.1074/jbc.M509066200

Wolfe, M.S., 2012. $\gamma$-Secretase inhibitors and modulators for Alzheimer's disease. J Neurochem 120, 89-98. https://doi.org/10.1111/j.1471-4159.2011.07501.x

Zhang, F., Jiang, L., 2015. Neuroinflammation in Alzheimer's disease. Neuropsychiatr Dis Treat 11, 243-56. https://doi.org/10.2147/NDT.S75546

Zhang, Y.W., Thompson, R., Zhang, H., Xu, H., 2011. APP processing in Alzheimer's disease. Mol Brain 4, 3. https://doi.org/10.1186/1756-6606-4-3

Zhou, R., Yang, G., Guo, X., Zhou, Q., Lei, J., Shi, Y., 2019. Recognition of the amyloid precursor protein by human $\gamma$-secretase. Science (80- ) 363(6428), eaaw0930. 
Graphical abstract

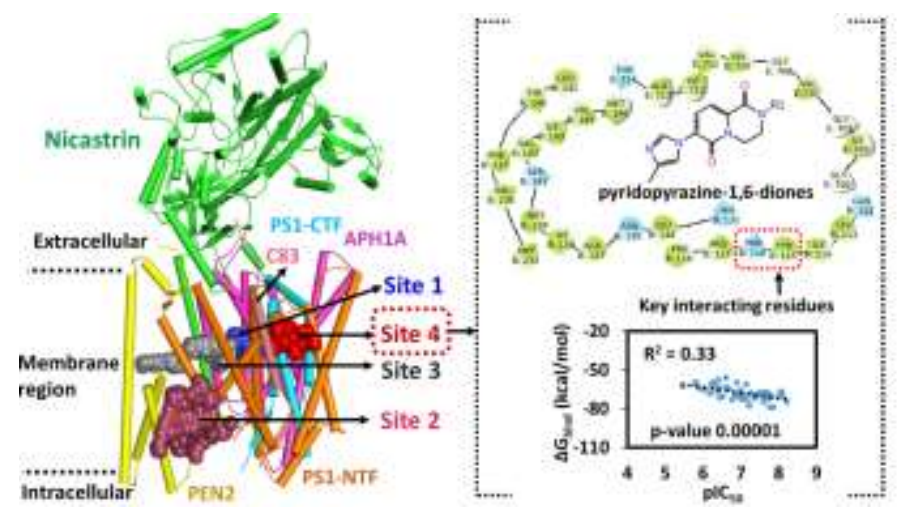

